\title{
Comparative genomic analysis of Pectobacterium carotovorum subsp. brasiliense SX309 provides novel insights into its genetic and phenotypic features
}

\author{
Lei Li ${ }^{1}$, Lifang Yuan ${ }^{1,2}$, Yanxia Shi ${ }^{1}$, Xuewen Xie ${ }^{1}$, Ali Chai ${ }^{1}$, Qi Wang ${ }^{2}$ and Baoju Li $^{1 *}$ (D)
}

\begin{abstract}
Background: Pectobacterium carotovorum subsp. brasiliense is a broad host range bacterial pathogen, which causes blackleg of potatoes and bacterial soft rot of vegetables worldwide. Production of plant cell wall degrading enzymes is usually critical for Pectobacterium infection. However, other virulence factors and the mechanisms of genetic adaptation still need to be studied in detail.

Results: In this study, the complete genome of $P$. carotovorum subsp. brasiliense strain SX309 isolated from cucumber was compared with eight other pathogenic bacteria belonging to the Pectobacterium genus, which were isolated from various host plants. Genome comparison revealed that most virulence genes are highly conserved in the Pectobacterium strains, especially for the key virulence determinants involved in the biosynthesis of extracellular enzymes and others including the type II and III secretion systems, quorum sensing system, flagellar and chemotactic genes. Nevertheless, some variable regions of the T6SS and the CRISP-Cas immune system are unique for $P$. carotovorum subsp. brasiliense.

Conclusions: The extensive comparative genomics analysis revealed highly conserved virulence genes in the Pectobacterium strains. However, several variable regions of type VI secretion system and two subtype Cas mechanism-Cas immune systems possibly contribute to the process of Pectobacterium infection and adaptive immunity.
\end{abstract}

Keywords: Pectobacterium carotovorum subsp. brasiliense, Comparative genomic analysis, Pathogenicity, Host genetic adaptation

\section{Background}

The bacterial genus Pectobacterium (formerly classified as the Erwinia genus) is a group of facultative anaerobic, Gram-negative, non-sporulating, motile bacteria belonging to the Pectobacteriaceae family [1-3]. The Pectobacterium genus consists of heterogeneous strains, To date, thirteen Pectobacterium species have been described, including $P$. carotovorum, $P$. atrosepticum, $P$. parmentieri, P. wasabiae, P. cacticida, P. betavasculorum, P. aroidearum, P. peruviense, P. polaris, and Candidatus P.

\footnotetext{
* Correspondence: libaojuivf@163.com

'Institute of Vegetables and Flowers, Chinese Academy of Agricultural

Sciences, Beijing 100081, China

Full list of author information is available at the end of the article
}

maceratum, P. zantedeschiae, $P$. punjabense, $P$. aquaticum $[2,4-7]$. The $P$. carotovorum species is a complex mix of strains that show divergent characteristics. Currently, $P$. carotovorum includes four subspecies: carotovorum, brasiliense, odoriferum, and actinidiae (newly proposed but as yet not validly published) $[2,3]$. Noteworthy, a number of strains previously classified as $P$. carotovorum have been separated from $P$. carotovorum recently and proposed as four new species, including $P$. aroidearum, $P$. peruviense, $P$. polaris and Candidatus $P$. maceratum [2]. To date, five complete $P$. carotovorum subspecies genome sequences have become publicly available, including $P$. carotovorum subsp. carotovorum PCC21 isolated from Brassica rapa ssp. pekinensis [8], P. 
carotovorum subsp. brasiliense $\mathrm{BC} 1$ isolated from Brassica rapa ssp. pekinensis [2] and P. carotovorum subsp. brasiliense BZA12 isolated from Cucumis sativus [9], P. carotovorum subsp. odoriferum BC S7 isolated from Brassica rapa ssp. pekinensis.

P. carotovorum subsp. brasiliense was originally reported in Brazil and has since been fully described [10]. Subsequently, $P$. carotovorum subsp. brasiliense has emerged as a global problem with reports from many regions of the world, including Canada, the United States, the Netherlands, Switzerland, South Africa, Kenya, South Korea, and Japan [11-13]. During 2014-2016, a devastating cucumber bacterial soft rot caused by $P$. carotovorum subsp. brasiliense occurred in northern China [14]. Nevertheless, very few studies have been focused on studying the complete genome of $P$. carotovorum subsp. brasiliense, and consequently, the pathogenicity and the genetic adaptation to the host of this subspecies remain largely unknown.

The symptoms caused by Pectobacterium infection include soft rot and wilts resulting from vascular invasion. Extensive studies on the Pectobacterium pathogens that infect vegetable crops and ornamental plants led to the identification of a number of virulence factors including extracellular degradative enzymes, diverse regulatory systems, and bacterial secretion systems, which are collectively contribute to the bacterial infections [15]. Pectobacteria spp. are pectinolytic pathogens, producing large quantities of plant cell wall degrading enzymes (PCWDEs). These include pectate lyase (Pel), polygalacturonase (Peh), cellulose (Cel), protease (Prt) and many others that are used to catalyze the breakdown of pectin, the primary plant cell wall component [16]. These exoenzymes are secreted via the type II secretion system (T2SS) [17] under the control of an $\mathrm{N}$-acyl homoserine lactone (AHL)-dependent quorum sensing (QS) system [18]. The virulence genes related to flagella biosynthesis, bacterial colonization, and swimming motility are also regulated by the QS system in P. carotovorum subsp. brasiliense [19]. The type III secretion system (T3SS) plays an important role in the pathogenesis of most plant pathogenic bacteria [20]. However, interestingly, most the T3SS-deficient Pectobacterium strains exhibit similar virulence to those T3SS-encoding strains in planta [21]. The type VI secretion systems (T6SS) possibly are also important for bacterial pathogenicity and host adaptation in some bacteria, which has been largely associated with various biological functions including biofilm formation, host adaptation and bacterial survival [22].

Most archaea and many bacteria protect themselves from infection by foreign genetic elements via Cas mechanism-Cas adaptive immunity systems to ensure their survival [23]. CRISPR-Cas immunity systems evolved three stages for function: adaptation, CRISPR RNA
(crRNA) biogenesis, and interference [24]. Currently, CRISPR-Cas systems include two classes, class 1 (types I, III and IV) that requires multi-Cas protein complexes for interference, and class 2 (types II, V and VI) that employs one single effector protein for interference [24]. In E. coli, the type I-E CRISPR-Cas interfering complex contains not only Cas1 and Cas 2 but also all other components of the effector Cascade complex (cas $\mathrm{A}$, cas $\mathrm{B}$, cas $\mathrm{C}$, cas $\mathrm{D}$, cas $\mathrm{E}$, and crRNA) and the Cas3 nuclease [25]. The subtype I-F Cas1 and Cas3 hybrid proteins interact with each other, suggesting a protein complex for adaptation and a role for the subtype I-F Cas 3 proteins in both the adaptation and interference steps of the CRISPR/Cas mechanism [26]. Previous studies have shown that the CRISPR/Cas system in $P$. atrosepticum encodes six proteins including Cas1, Cas3, Csy1, Csy2, Csy3 and Csy4 [26]. Nevertheless, the biological functions of the CRISPR/Cas systems remain poorly understood in P. carotovorum subsp. brasiliense.

In this study, the complete genome sequence of $P c b$ strain SX309 that is highly virulent in a wide range of host plant species was sequenced, annotated and compared with the representative genomes of other Pectobacterium species and $P$. carotovorum subspecies, with a particular focus on virulence factors, regulatory mechanisms and potential genetic adaptation to the host. Through comparative genomic analysis, we found that the genes encoding PCWDEs, T2SS, T3SS, T6SS, QS system, two-component system and LPS are probably major virulence factors, and the CRISPR/Cas system may be involved in adaptive immunity. Characterization of these functional determinants among the Pectobacterium pathogens will provide novel insights into hostpathogen interactions.

\section{Methods}

\section{Bacterial strains and genomic DNA extraction}

P. carotovorum subsp. brasiliense SX309 (original number: HG1501090306) was isolated from cucumber fruit showing typical soft rot symptoms in Shanxi Province of China in February 2015 [14]. The phenotypic, biochemical characterization and host range were tested and analyzed by Meng et al [14]. This strain was typically incubated in NB (Nutrient Broth, BD, USA) liquid media at $28^{\circ} \mathrm{C}$ with shaking for $48 \mathrm{~h}$. High-quality genomic DNA was extracted from the cultured bacteria using a QIAamp ${ }^{\circ}$ NNA Mini Kit (Qiagen, Valencia, CA).

\section{Whole-genome sequencing}

The complete genome sequencing of $P$. carotovorum subsp. brasiliense SX309 was performed at the Beijing Allwegene Technology Corporation using a Pacific Biosciences (PacBio) RS II platform with a Single Molecule Real-Time (SMRT). A SMRTbellTM template library with a $20 \mathrm{~kb}$ insert-size was constructed. The library was 
then sequenced using $\mathrm{C} 4$ sequencing chemistry and P6 polymerase with one SMRT cell, and the reads were trimmed on quality and length. The resulting clean reads were assembled de novo with the PacBio SMRT Analysis software [27] (version 2.3.0). The graphical views of genome alignments were generated using CGView software [28].

\section{Gene prediction and annotation}

Protein coding sequences (CDS) were predicted using the NCBI Prokaryotic Genome Annotation Pipeline (PGAP, https://www.ncbi.nlm.nih.gov/genome/annotation_prok/) [29]. tRNA and rRNA genes were identified using tRNAscan-SE [30] version 2.0 and RNAmmer [31] version 1.2. The functions of the predicted proteins were annotated based on a BLASTP search against the NonRedundant Protein Database (NR, https://blast.ncbi.nlm. nih.gov/Blast.cgi), the Pfam protein family database (http://pfam.xfam.org/), the Cluster of Orthologous Groups of proteins database (COG, https://www.ncbi. nlm.nih.gov/COG/), and the Kyoto Encyclopedia of Genes and Genomes database (KEGG, http://www.genome.jp/kegg/). Furthermore, sequence analysis was improved using the RAST analysis platform [32]. Putative signal peptides and transmembrane helices were predicted using SignalP 4.0 [33] and TMHMM 2.0 [34], respectively. The metabolic pathways were examined using a KEGG Automatic Annotation Server (KAAS, http:// www.genome.jp/tools/kaas/).

\section{Phylogenetic analysis}

Phylogenetic relationship analyses were determined from the multilocus sequence analysis (MLSA) on six housekeeping genes including $16 \mathrm{~S}$ rRNA, gapA, gyrA, atpD, rpoA, and rho from twenty Pectobacterium spp., seven Dickeya spp., and eight Erwinia spp. GenBank accession numbers associated with the housekeeping loci of all of the strains can be found in Additional file 5: Table S3. The gene sequences were aligned using MUSCLE software and trimmed to remove ambiguously aligned regions. Subsequently, six housekeeping gene sequences were concatenated in the same order using SequenceMatrix. The phylogenetic tree was constructed using the maximum likelihoods method derived from MEGA 6.0 software [35], and 1,000 bootstrap replicates were included in a heuristic search with a random tree and the tree bisection-reconnection branch-swapping algorithm.

\section{Comparative analysis}

According to the phylogenetic analysis, we selected eight closely related species or subspecies with released complete genomes including $P$. atrosepticum SCRI1043, P. parmentieri RNS08.42.1A, P. parmentieri SCC3193, $P$. wasabiae CFBP 3304, P. carotovorum subsp. brasiliense
BC1, P. carotovorum subsp. brasiliense BZA12, P. carotovorum subsp. carotovorum PCC21, and P. carotovorum subsp. odoriferum BC S7 for genome comparison. Average nucleotide identities (ANI) values were computed for pairwise genome comparison using the OrthoANIu Algorithm (https://www.ezbiocloud.net/tools/orthoaniu) [36]. In silico DNA-DNA hybridization (DDH) was calculated using the Genome-to-Genome Distance Calculator (GGDC) (http://ggdc.dsmz.de/ggdc.php\#) [37]. Complete genome comparisons were conducted using the progressive alignment option of the Mauve 2.3.1 comparison software [38] with the SX309 genome as the reference genome. Furthermore, synteny plots were also generated as alignments of the complete genome nucleotide sequences using MUMmer 3.22 [39]. To identify the set of common genes for the Pectobacterium genus and the set of genes unique to each species or subspecies, comparative analyses at the protein level were performed using an all-against-all comparison of the annotated genomes using BLASTP [40], and ortholog gene clustering analysis was implemented with the default settings [41]. Venn diagrams were created using $R$ project language [42]. The comparative analysis of the T3SS effectors, QS system, TCS, and CRISPR/Cas system were BLASTed at the protein level using T3DB [43], SigMol [44], P2CS database [45], and CRISPRs Finder tool [46], respectively. The targets of the spacers were identified using ViroBLAST (https://indra.mullins. microbiol.washington.edu/viroblast/viroblast.php) and local BLAST analysis against NCBI plasmid genomes (ftp://ftp.ncbi.nih.gov/refseq/release/plasmid/).

\section{Extracellular enzyme assays}

Plate assays for the activity of Pel, Peh, Cel, and Prt were conducted as described by Chatterjee et al. [17] (1995) with slight modifications. Wells were bored in the agarose medium with a No. 2 cork borer, and the bottoms were sealed with $0.8 \%(\mathrm{w} / \mathrm{v})$ of molten agarose. Bacterial cells were grown in NB liquid medium overnight at $28^{\circ} \mathrm{C}$ and adjusted to $\mathrm{OD}_{600}=0.8$. Samples were applied to the wells, and the plates were incubated for $24 \mathrm{~h}$ at $28^{\circ} \mathrm{C}$ for Pel, Peh, and Cel and for $48 \mathrm{~h}$ for Prt. The Pel and Peh plates were developed with $4 \mathrm{~N} \mathrm{HCl}$, and the Cel plates were stained with $0.1 \%(\mathrm{w} / \mathrm{v})$ Congo red solution for $10 \mathrm{~min}$ and then washed with $1 \mathrm{M} \mathrm{NaCl}$ solution three times. Haloes in the Prt plates became visible without any further treatment. Each treatment was repeated three times, and all of the experiments were repeated three times.

\section{Virulence assays}

The virulence and symptom development caused by $P$. carotovorum subsp. brasiliense SX309 were assessed in cucumber plants (Cucumis sativus) and potato plants 
(Solanum tuberosum). Cucumber and potato stems were stab-inoculated with $10 \mu \mathrm{L}$ of approximately $1 \times 10^{8}$ $\mathrm{CFU} / \mathrm{mL}$ bacterial suspensions of the SX309 strain. They were then incubated in a moist chamber at $28^{\circ} \mathrm{C}$, and the appearance of the symptoms was periodically observed. Sterilized distilled water was used for the negative control inoculations. For each inoculation experiment, three plants were used, and the experiments were repeated three times.

\section{Microscopic analysis}

For transmission electron microscope (TEM) observation, bacterial cells were negatively stained using $1 \%$ uranium acetate on collodion-coated 100-mesh grids. The samples were visualized using a transmission electron microscope Hitachi-7700 (Hitachi High-Technologies Corporation, Tokyo). For fluorescence electron microscope (FEM) observation, the plasmid pSMC21 containing the $g f p$ gene was used to generate a GFP-tagged $P$. carotovorum subsp. brasiliense strain [47]. The plasmid was introduced into the bacterial cells using electroporation. The GFP-tagged SX309 strain was then visualized using a fluorescence microscope Olympus BX51. For scanning electron microscope (SEM) observation, bacterial cells in exponential and stationary phases were fixed using $2.5 \%$ glutaraldehyde. Samples were observed using a scanning electron microscope Hitachi-S3400N.

\section{Results}

\section{Organism information}

P. carotovorum subsp. brasiliense SX309 is a facultative anaerobic, Gram-negative, non-sporulating bacterium belonging to the Pectobacteriaceae family (Additional file 1: Table S1). SX309 strain is rod-shaped with a length of $1.5-2 \mu \mathrm{m}$ and a diameter of $0.5-0.8 \mu \mathrm{m}$. It is motile by using peritrichous flagella (Additional file 2: Figure S1). Strain SX309 can utilize several carbon sources and grow in $5 \% \mathrm{NaCl}$ [14]. Pathogenicity tests showed that SX309 is highly virulent in various host plants including some important vegetable crops such as cucumbers and potatoes (Additional file 3: Figure S2). Minimum information about the genome sequence (MIGS) of P. carotovorum subsp. brasiliense SX309 is summarized in Additional file 1: Table S1 [48].

\section{General genomic features of $P$. carotovorum subsp. brasiliense SX309}

A total of 37,555 clean reads with an average length of $12,020 \mathrm{bp}$ and an $\mathrm{N}_{50}$ size of $16,273 \mathrm{bp}$ were generated. Assembly of the clean reads resulted in a single contig with 90.89-fold coverage on average without any gap (Additional file 4: Table S2). Thus, the genome of P. carotovorum subsp. brasiliense SX309 is composed of a single circular chromosome that is $4,966,299$ bp in size with no apparent autonomous plasmids (Additional file 5: Table S3 and Fig. 1). The average $\mathrm{G}+\mathrm{C}$ content of the whole genome is $52.18 \%$, which is similar to $P$. carotovorum subsp. brasiliense $\mathrm{BC} 1$ (51.8\%), P. carotovorum subsp. brasiliense BAZ12 (52.00\%), $P$. carotovorum subsp. carotovorum PCC21 (52.18\%) and P. carotovorum subsp. odoriferum BC S7 (51.80\%) (Table 1). In total, 4, 455 open reading frames (ORFs) have been predicted in the genome of SX309. In addition to 4,252 protein coding genes (CDSs), the chromosome contains 104 RNA genes including 76 tRNA genes, 22 rRNA operons, 6 ncRNAs and 99 pseudogenes (Additional file 5: Table S3). These annotated genes are transcribed in the positive and negative directions from the perspective of the direction of DNA replication, respectively (Fig. 1). Using Pfam, SignalP, and the TMHMM database, 3,849 (86.40\%), 409 (9.18\%), and $19(0.43 \%)$ of the ORFs could be classified to different groups, respectively (Additional file 5: Table S3).

Functional categorization of 4,252 CDSs were analyzed using the Cluster of Orthologous Groups of proteins (COG). The results showed that 3,474 (77.98\%) of the predicted genes of SX309 were assigned to the COG categories (Additional file 5: Table S3). Among these assigned genes, $42.47 \%$ are related to metabolism, $20.63 \%$ to cellular processes and signaling, and $17.13 \%$ to information storage and processing. However, 19.77\% of the genes cannot be assigned in COG categories because their features and functions remain unknown (Table 2). Moreover, the RAST annotation has assigned 2,406 genes of SX309 strain into 529 subsystems. Most of the genes are associated with carbohydrates (15.83\%), amino acids and derivatives (12.74\%), protein metabolism (8.98\%), cofactors, vitamins and pigments (7.66\%), RNA metabolism (7.13\%), membrane transport (5.96\%), and stress response (4.29\%) (Additional file 6: Figure S3).

\section{Comparison of the $P$. carotovorum subsp. brasiliense SX309 genome with other completely sequenced Pectobacterium spp.}

For comparative genomic analysis of $P$. carotovorum subsp. brasiliense SX309, eight publicly available complete genomes of Pectobacterium species or subspecies including $P$. carotovorum subsp. brasiliense $\mathrm{BC} 1$ (GenBank: CP009769.1 ), P. carotovorum subsp. brasiliense BZA12 (GenBank:CP024780.1), P. carotovorum subsp. carotovorum PCC21 (GenBank: CP003776.1), P. carotovorum subsp. odoriferum BC S7 (GenBank: CP009678.1), P. atrosepticum SCRI1043 (GenBank: BX950851.1), P. wasabiae CFBP 3304 (GenBank: CP015750.1), P. parmentieri RNS08.42.1A (GenBank: CP015749.1), and P. parmentieri SCC3193 (GenBank: CP003415.1) have been selected (Table 1). The genome size ranged from 4.84 to $5.16 \mathrm{Mbp}$, with a G+C content of $50.40-52.18 \%$ and $3855-4472$ 


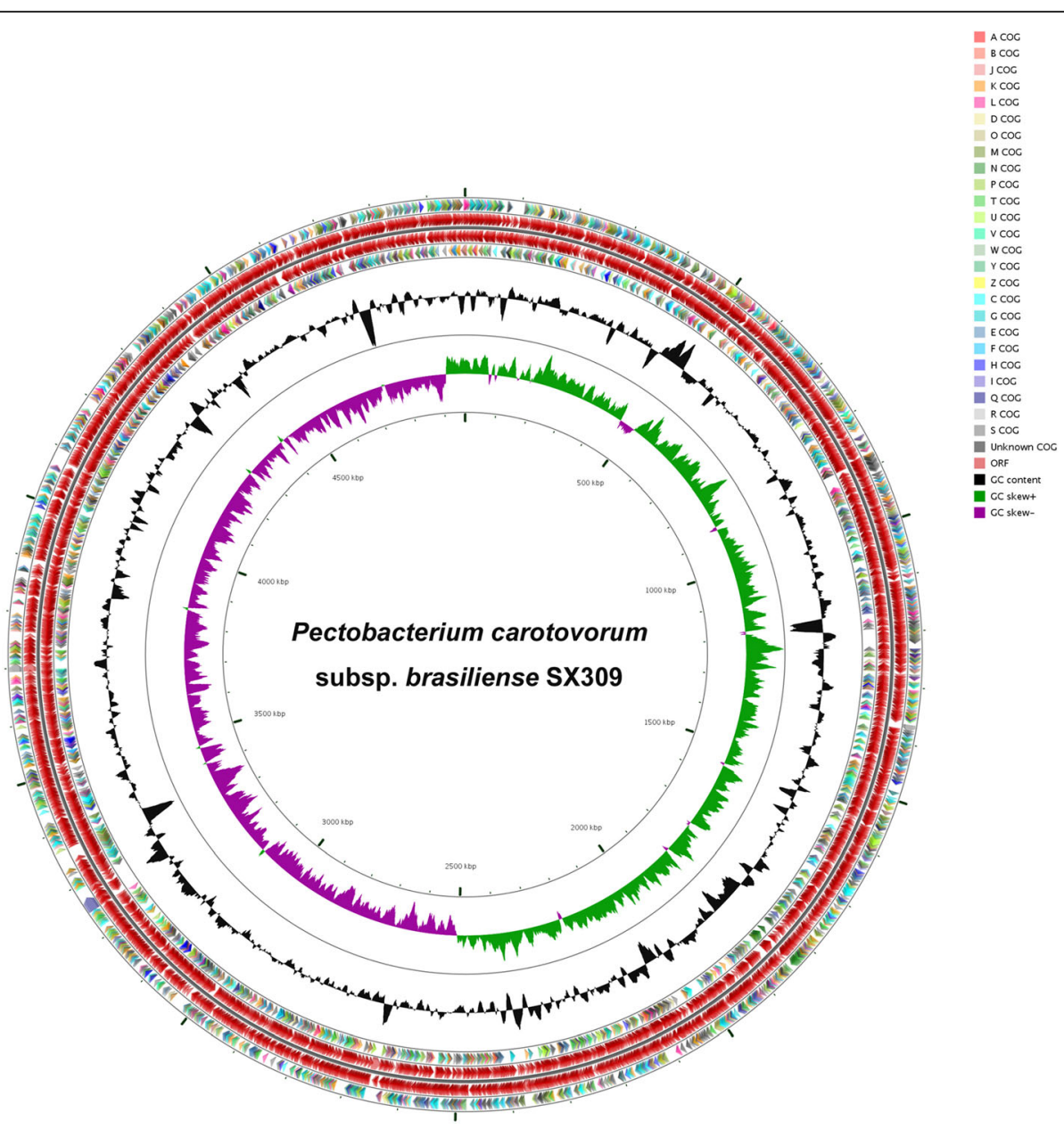

Fig. 1 Graphical circular map of the P. carotovorum subsp. brasiliense SX309 genome performed with CGview Server. From outside to center, ring 1 and 4 show protein-coding genes oriented in the forward (colored by COG categories) and reverse (colored by COG categories) directions, respectively. Ring 2 and 3 denote genes on forward and reverse strand. Ring 5 shows G+C\% content plot (black) and the inner most ring shows GC skews, where green indicates positive values and purple indicates negative values

Table 1 Genomic features of Pectobacterium carotovorum subsp. brasiliense SX309 and other Pectobacterium spp

\begin{tabular}{|c|c|c|c|c|c|c|c|c|c|}
\hline Features & SX309 & $\mathrm{BC} 1$ & BAZ12 & PCC21 & BC S7 & SCRI1043 & SCC3193 & CFBP3304 & RNS08.42.1A \\
\hline Size (bp) & $4,966,299$ & $4,920,350$ & $4,924,809$ & $4,842,771$ & $4,933,575$ & $5,064,019$ & $5,164,411$ & $5,043,228$ & $5,030,841$ \\
\hline $\begin{array}{l}\mathrm{G}+\mathrm{C} \text { content } \\
(\%)\end{array}$ & 52.18 & 51.80 & 52.00 & 52.18 & 51.80 & 51.00 & 50.40 & 50.60 & 50.40 \\
\hline Replicons & $\begin{array}{l}\text { One } \\
\text { chromosome }\end{array}$ & $\begin{array}{l}\text { One } \\
\text { chromosome }\end{array}$ & $\begin{array}{l}\text { One } \\
\text { chromosome }\end{array}$ & $\begin{array}{l}\text { One } \\
\text { chromosome }\end{array}$ & $\begin{array}{l}\text { One } \\
\text { chromosome }\end{array}$ & $\begin{array}{l}\text { One } \\
\text { chromosome }\end{array}$ & $\begin{array}{l}\text { One } \\
\text { chromosome }\end{array}$ & $\begin{array}{l}\text { One } \\
\text { chromosome }\end{array}$ & $\begin{array}{l}\text { One } \\
\text { chromosome }\end{array}$ \\
\hline Total genes & 4,455 & 4,472 & 4,476 & 4,340 & 4,340 & 4,615 & 4,821 & 4,579 & 4,564 \\
\hline $\begin{array}{l}\text { Predicted no. } \\
\text { of CDS }\end{array}$ & 4,351 & 4,267 & 4,251 & 4,263 & 3,855 & 4,381 & 4,449 & 4,472 & 4,457 \\
\hline $\begin{array}{l}\text { Ribosomal } \\
\text { RNA }\end{array}$ & 22 & 22 & 22 & 22 & 22 & 22 & 22 & 22 & 22 \\
\hline Transfer RNA & 76 & 77 & 76 & 7 & 77 & 77 & 77 & 77 & 77 \\
\hline Other RNA & 6 & 9 & 7 & 6 & 1 & 10 & 7 & 8 & 8 \\
\hline Pseudogene & 99 & 97 & 120 & 121 & 385 & 125 & 266 & 184 & 62 \\
\hline $\begin{array}{l}\text { GenBank } \\
\text { sequence }\end{array}$ & СР020350.1 & СР009769.1 & СР024780.1 & СР003776.1 & СР009678.1 & BX950851.1 & СР003415.1 & СР015750.1 & СР015749.1 \\
\hline
\end{tabular}


Table 2 Number of genes associated with general COG functional categories

\begin{tabular}{|c|c|c|c|c|}
\hline Category & Code & Value & $\%$ age & Description \\
\hline \multirow[t]{8}{*}{ Metabolism } & C & 208 & 5.08 & Energy production and conversion \\
\hline & E & 437 & 10.68 & Amino acid transport and metabolism \\
\hline & $\mathrm{F}$ & 82 & 2.00 & Nucleotide transport and metabolism \\
\hline & G & 361 & 8.82 & Carbohydrate transport and metabolism \\
\hline & $\mathrm{H}$ & 156 & 3.81 & Coenzyme transport and metabolism \\
\hline & । & 87 & 2.13 & Lipid transport and metabolism \\
\hline & P & 322 & 7.87 & Inorganic ion transport and metabolism \\
\hline & Q & 85 & 2.08 & Secondary metabolites biosynthesis, transport and catabolism \\
\hline \multirow[t]{10}{*}{ Cellular processes and signaling } & D & 37 & 0.90 & Cell cycle control, Cell division, chromosome partitioning \\
\hline & M & 215 & 5.25 & Cell wall/membrane biogenesis \\
\hline & $\mathrm{N}$ & 104 & 2.54 & Cell motility \\
\hline & $\mathrm{O}$ & 139 & 3.40 & Posttranslational modification, protein turnover, chaperones \\
\hline & T & 195 & 4.77 & Signal transduction mechanisms \\
\hline & $U$ & 114 & 2.79 & Intracellular trafficking and secretion \\
\hline & V & 40 & 0.98 & Defense mechanisms \\
\hline & W & 0 & 0.00 & Extracellular structures \\
\hline & Y & 0 & 0.00 & Nuclear structure \\
\hline & Z & 0 & 0.00 & Cytoskeleton \\
\hline \multirow[t]{5}{*}{ Information storage and processing } & J & 180 & 4.40 & Translation, ribosomal structure and biogenesis \\
\hline & A & 1 & 0.02 & RNA processing and modification \\
\hline & B & 0 & 0.00 & Chromatin structure and dynamics \\
\hline & K & 337 & 8.24 & Transcription \\
\hline & L & 183 & 4.47 & Replication, recombination and repair \\
\hline \multirow[t]{3}{*}{ Poorly characterized } & $\mathrm{R}$ & 479 & 11.71 & General function prediction only \\
\hline & S & 330 & 8.06 & Function unknown \\
\hline & - & 980 & 22.00 & Not in COGs \\
\hline
\end{tabular}

predicted CDS (Table 1). Similarly, the genomes of the seven Pectobacterium strains contain only one single chromosome without a plasmid.

To understand the relationships of $P$. carotovorum subsp. brasiliense SX309 with genome sequenced strains within the Pectobacterium, Dickeya, and Erwinia genera, a phylogenetic tree was constructed based on $16 \mathrm{~S}$ rRNA and five housekeeping genes $(\operatorname{gap} \mathrm{A}, \operatorname{gyr} \mathrm{A}, \operatorname{atp} \mathrm{D}, r p o \mathrm{~A}$, rho) (Additional file 7: Table S4 and Additional file 8: Figure S4). As expected, the twenty Pectobacterium strains, seven Dickeya strains, and eight Erwinia strains were clustered into three major clades. In practice, $P e c$ tobacterium spp. are considered as broad-host range pathogens, except that $P$. atrosepticum has been reported almost exclusively from potatoes (Solanum tuberosum) and $P$. betavasculorum exclusively from sugar beets (Beta vulgaris). P. carotovorum has a broader host range and less restricted survival conditions than $P$. atrosepticum, $P$. parmentieri, and $P$. wasabiae, which are specialized to cause disease in one or few host plants only [49]. Strain SX309 is able to infect a wide range of plant species [14], which might explain the close relationship between SX309 and other P. carotovorum subsp. The Dickeya group clearly formed three distinct sub-clades. Strain EC1 was the closest homolog to $D$. zeae Ech586, followed by D. chrysanthemi Ech1591. In contrast, strain IPO2222 was the closest homolog to $D$. dadantii 3937, followed by D. solani ND14b. The Pectobacterium and Dickeya species are close relatives and were formerly classified as Erwinia spp. [6]. Our results of phylogenetic analysis agree with the previous findings. Thus, phylogenetic analysis based on multilocus sequences provided a strong support and an accurate classification for the species. Strain SX309 was assigned to the clade of $P$. carotovorum, which includes $\mathrm{BC} 1$ and BAZ12 belonging to $P$. carotovorum subsp. brasiliense.

The average nucleotide identity (ANI), and the genome-to-genome distance calculator, or in silico DDH (is DDH), are two of the most widely accepted bioinformatics tools that calculate whole-genome sequence 
similarities by comparing genomic data. A recent study showed that approximately $\geq 96 \%$ ANI values and $\geq 70 \%$ DDH values consistently grouped genomes originating from strains of the same species together [3]. In this study, we performed additional calculations on the ANI and DDH values among the representative Pectobacterium strains (Additional file 9: Table S5). The results showed that the ANI and DDH values between strains SX309 and BC1 were approximately $97.43 \%$ and $77.70 \%$ respectively. These findings indicated that strains SX309 and $\mathrm{BC} 1$ were clustered closely and occupied the same taxonomic position. Lower ANI and DDH values were obtained when BC S7, CFBP3304, RNS08.42.1A and SCC3193 were used as reference genomes.

To evaluate the evolutionary distance among these sequenced strains within the Pectobacterium genus, the whole genome sequences were compared using Mauve software. At the subspecies level, the genome sequence of strain SX309 was aligned to two other P. carotovorum subsp. brasiliense (BC1 and BZA12) and its closest fully sequenced relatives, $P$. carotovorum subsp. carotovorum PCC21 and P. carotovorum subsp. odoriferum BC S7 (Fig. 2a and 2b). This alignment showed that the SX309 genome is much more similar to the $\mathrm{BC} 1$ than to the BZA12 within the brasiliense subsp. At the subspecies level, the SX309 genome is much more similar to the PCC21 than to the BC S7 genome, supporting the relationship described above. In comparison to PCC21, there is no significant gene insertion or deletion of large regions in $P$. carotovorum subsp. brasiliense SX309, but large local collinear blocks (LCB) inversion occurred. Comparison of the whole genome sequences at the species level revealed that the locations of homologous genes were different in SX309 and P. atrosepticum SCRI1043, P. parmentieri SCC3193, P. parmentieri RNS08.42.1A, and P. wasabiae CFBP 3304 (Fig. 2C). Regions with low similarity among the genome occurred frequently, and distributed randomly. Additionally, the

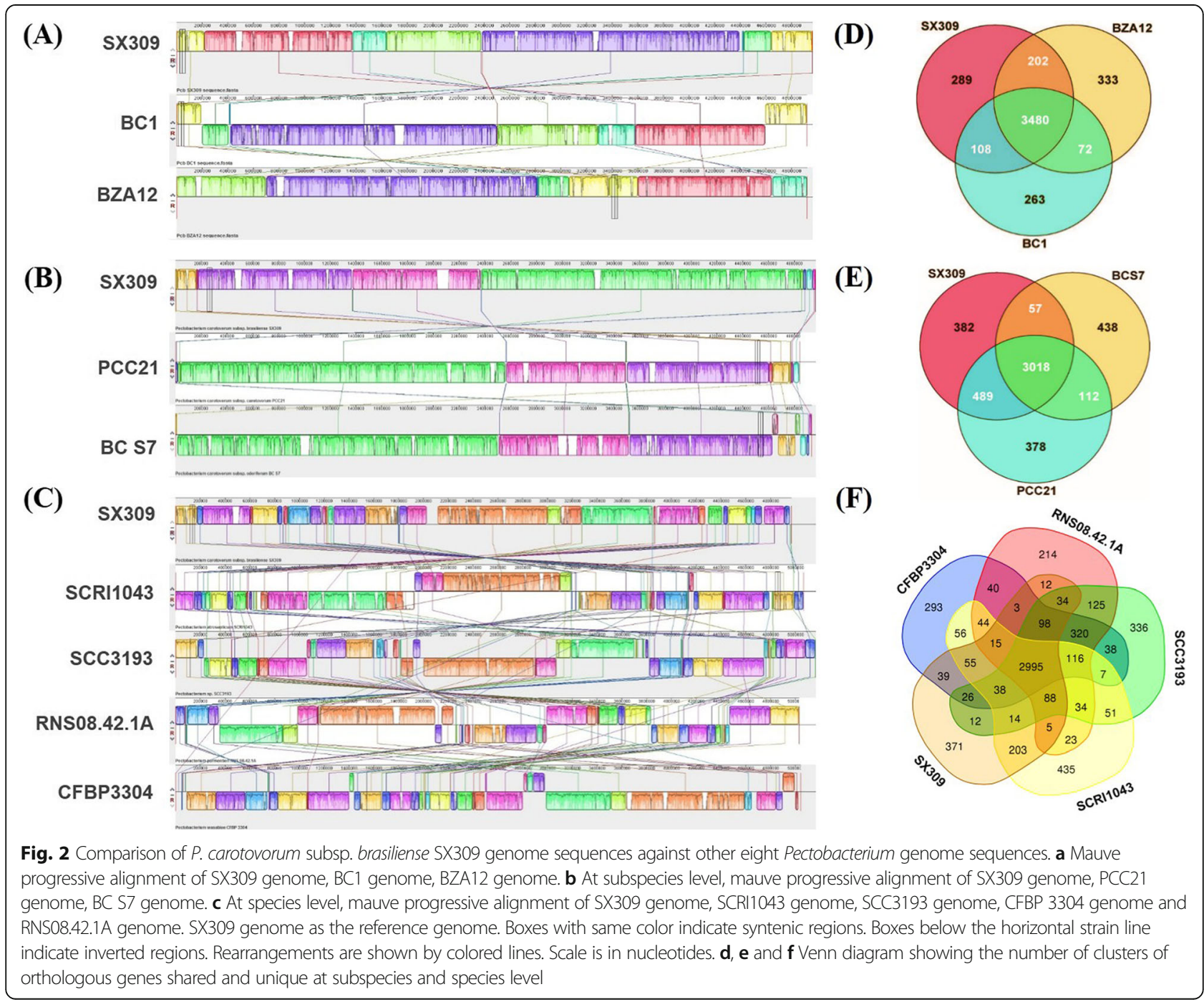


synteny plot of the pairwise alignment supports the previous analysis that strain SX309, PCC21 and BC S7 belong to the same subspecies. Moreover, the SX309 genome is more similar to SCRI1043 than the other three Pectobacterium species. However, there were large numbers of changes in the LCB between SX309 and SCRI1043 during the evolution of the species (Additional file 10: Figure S5).

To identify the specific genes in P. carotovorum subsp. brasiliense SX309, we compared its genome sequence to the complete genome sequences of the eight strains that have been released (Fig.2). As shown in Fig. 2d, there were 3,480 conserved genes shared by the three strains of $P$. carotovorum subsp. brasiliense. SX309 shared 202 genes with BAZ12 and had 108 genes with counterparts in the $\mathrm{BC} 1$ genome. Furthermore, 289 unique genes were present in the genome of SX309 and the functions of most unique genes are still unknow at the moment. At the subspecies level, the core genome among SX309, PCC21 and BC S7 is composed of 3,018 orthologous genes, which represents approximately $70.98 \%$ of all the predicted genes. In addition, 382 unique genes $(8.98 \%$ of the predicted genes) present in the SX309 genome were not found in the other two genomes within the same subspecies (Fig. 2e). The analysis also revealed that a core genome consisting of 2,995 genes are common to all five species, while $P$. carotovorum subsp. brasiliense SX309 has 371 unique genes (Fig. 2f).

\section{Plant cell wall-degrading enzymes}

Extracellular enzyme assays showed that strain SX309 can produce pectate lyase (Pel), polygalacturonase (Peh), cellulase (Cel), and protease (Prt) (Additional file 11: Figure S6). Genome sequencing revealed the presence of the genes for the synthesis and secretion of plant cell wall-degrading enzymes in strain SX309. A total 59 known or putatively related genes encoding pectinases, cellulases and proteinases were identified in the SX309 genome. Briefly, the genome of SX309 contains 20 genes encoding pectin degradation enzymes, including pelN, $p e l \mathrm{I}, p e l \mathrm{~A}, p e l \mathrm{Y}, p e l \mathrm{C}, p e l \mathrm{~B}, p e l \mathrm{Z}, p e l \mathrm{~W}$, and $p e l \mathrm{X}$ for pectate lyases, $p n l$ for a pectin lyase, pemA and pemB for pectinesterase, paeX and paeY for pectin acetylesterase, $p e h \mathrm{X}, p e h \mathrm{~N}, p e h \mathrm{~A}$, and pehK for polygalacturonases, $o g l$ for a oligogalacturonide lyase, and rhiE for a rhamnogalacturonate lyase (Additional file 12: Table S6). These pectin degradation genes were highly conserved in various Pectobacterium species, except that pehK was absent in $P$. parmentieri SCC3193 and P. parmentieri RNS08.42.1A. Therefore, the production of PCWDEs may be a hallmark of infection for Pectobacterium spp.

Similarly, 16 genes in SX309 are involved in cellulose degradation, including two endoglucanase-encoding genes $c e l \mathrm{~V}$ and $b c s \mathrm{Z}$, five beta-glucosidase-encoding genes $b g l \mathrm{~A}, b g l \mathrm{~B}, b g l \mathrm{D}, n a g \mathrm{Z}$, and $c e l \mathrm{H}$, and an alphaglucosidase-encoding gene $\mathrm{lfaA}$. These genes, associated with oligosaccharide degradation, are conserved in Pectobacterium stains, except that $c e l \mathrm{H}$ was absent in $P$. parmentieri SCC3193 and $P$. parmentieri RNS08.42.1A (Additional file 12: Table S6). Additionally, an operon of eight genes encoding cellulose synthetase, including $b c s \mathrm{C}, b c s \mathrm{~B}, b c s \mathrm{~A}, b c s \mathrm{Q}, b c s \mathrm{R}, b c s \mathrm{E}, b c s \mathrm{~F}$, and $b c s \mathrm{G}$, was also identified in SX309.

Moreover, 23 genes encoding proteases were detected in the SX309 genome (Additional file 12: Table S6). Among them, the six protease-encoding genes, including $p r t 1, p r t \mathrm{C}, p r t \mathrm{~W}, \operatorname{deg} \mathrm{P}, \operatorname{deg} \mathrm{Q}$, and $g l p \mathrm{G}$ encode serralysin homologs that share more than $90 \%$ similarity at the amino acid level. The four ATP-dependent Clp proteaseencoding genes, including $c l p \mathrm{~S}, c l p \mathrm{~A}, c l p \mathrm{X}$, and $c l p \mathrm{P}$, were identified, and a lon protease encoding gene lon was also found in SX309.

\section{Secretion systems}

The genome of SX309 contains a wide variety of secretion systems, which are closely related to bacterial pathogenicity (Additional file 13: Table S7).According to the comparative analysis, the $P$. carotovorum subsp. brasiliense SX309 chromosome contains a highly conserved T2SS gene cluster ( $g s p$ CDEFGHIJKLMN and outOSB) (Fig. 3), covering $17.669 \mathrm{~kb}$ with 15 ORFs. The gsp gene cluster shares an average of $90 \%$ similarity with that of various Pectobacterium species at the amino acid level (Additional file 13: Table S7), except that $g s p \mathrm{C}$ is absent in $P$. carotovorum subsp. odoriferum BC S7, and $g s p \mathrm{~N}$ is absent in P. parmentieri SCC3193 and P. parmentieri RNS08.42.1A. The outOSB genes are also highly conserved among Pectobacterium spp., except that the out $\mathrm{O}$ gene is replaced by BCS7_14675 encoding a hypothetical protein in strain BC S7. Among the six Pectobacterium spp., the common characteristics of T2SS is that it contains $p e l$ and $p e h \mathrm{~K}$ genes upstream of $g s p \mathrm{C}$, except the pel gene is absent in strains SCC3193 and RNS08.42.1A (Fig. 3). The genes involved in the secretion-signal recognition particle (Sec-SRP) system are highly conserved in all six Pectobacterium spp., except secA and $s e c \mathrm{E}$, which are absent in strain BC S7.

Many plant pathogenic bacteria inject multiple effector proteins into plant cells via the Type III secretion system for successful infection. A large hrp/hrc gene cluster of 33 genes was identified in the genome of $P$. carotovorum subsp. brasiliense SX309. SX309 shares high similarities in the $h r p / h r c$ gene cluster sequences with the other Pectobacterium species,. However, there are certain variations. For example, the $h r p / h r c$ gene cluster is absent in P. parmentieri SCC3193 and P. parmentieri RNS08.42.1A but present in the other three species including $P$. carotovorum subsp. carotovorum PCC21, P. carotovorum subsp. 


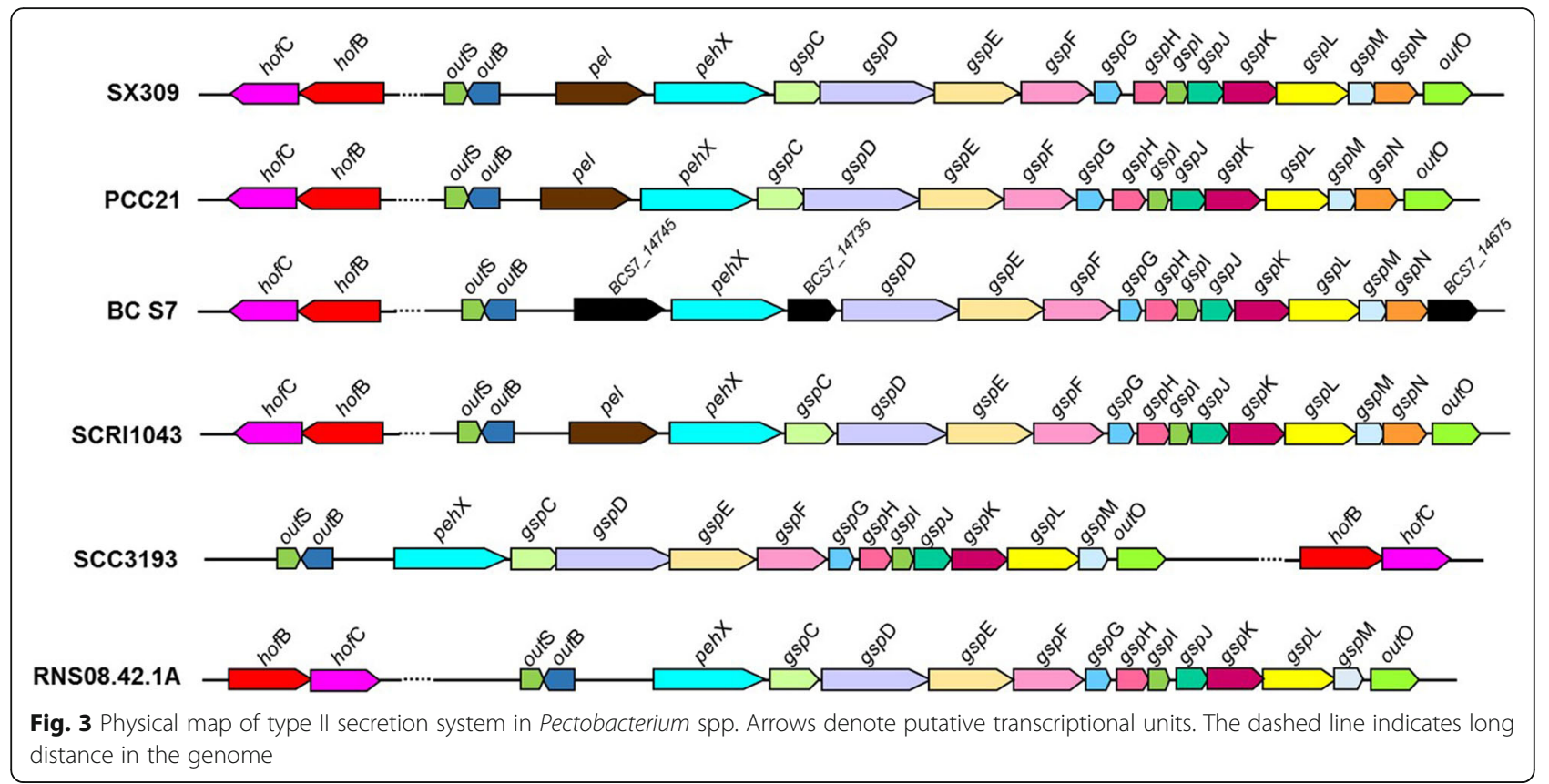

odoriferum BC S7, and P. atrosepticum SCRI1043 (Additional file 13: Table S7). In addition, the $d s p \mathrm{E}$ and $d s p \mathrm{~F}$ genes encoding the AvrE-family T3SS effectors are also conserved among Pectobacterium spp., except that $d s p \mathrm{E}$ is absent in P. parmentieri SCC3193 and P. parmentieri RNS08.42.1A, but $d s p \mathrm{~F}$ is absent in strains BC S7, SCC3193, and RNS08.42.1A. Given that most key hrp/hrc genes are highly conserved in strain SX309, it is highly possible that the T3SS in SX309 could play certain roles in the bacterial pathogenicity, which awaits further investigations.

The type VI secretion system (T6SS) is widely present in many Gram-negative bacteria, delivering toxic effector proteins into adjacent bacterial or host cells. In this study, the T6SS gene cluster of P. carotovorum subsp. brasiliense SX309 was found to have 33 genes, among which 15 were identified as core genes (Fig. 4). The 15 core T6SS genes are highly conserved in various Pectobacterium species and subspecies. Biological functions have been assigned for the outer membrane lipoprotein (VasD), Inner membrane proteins (ImpL and ImpK), ATPase (ClpV), and regulatory proteins or structure proteins (ImpB, ImpC, TssE, ImpG, ImpH, ImpI, ImpJ, VasH, VasI, VasJ, and VasL) [50] (Additional file 14: Table S8). In addition to the 15 core T6SS genes, there are five $v g r G$ and $13 h c p$ genes that encode extracellular structural components of the secretion machine and specific effectors in SX309 genome. Nevertheless, the copy numbers of $v g r \mathrm{G}$ and $h c p$ genes substantially varied among different Pectobacterium species and subspecies (Additional file 14: Table S8).

\section{Quorum-sensing systems}

Quorum sensing (QS) is a cell-population densitydependent regulatory mechanism in which gene expression is coupled to the accumulation of chemical signaling molecules known as autoinducers (AI) [51]. In P. carotovorum, two QS systems exist that are specified by the nature of the chemical signals involved: the $N$-acyl homoserine lactones (AHLs)- and the autoinducer-2 (AI-2)- dependent signaling systems [52]. In this study, a positive reaction was observed in the AHL biosensor Agrobacterium tumefaciens NTL/ pZLR4 (Additional file 15: Figure S7A), suggesting that SX309 could produce the AHL signals. A BLAST search of the SX309 genome revealed only one copy of carI (B5S52_ 21425) and a conserved luxR homolog (B5S52_21420) designated as $\operatorname{expR}$ (Additional file 16: Table S9). The proteins encoded by $\operatorname{carI} / \exp \mathrm{R}$ have high sequence identity with the AHL biosynthetic and receptor proteins ExpI/ExpR of Pectobacterium spp. (more than 90\%, respectively) at the amino acid level, except that they have low similarity with P. parmentieri SCC3193. In addition, P. carotovorum subsp. brasiliense SX309 has a functional luxS gene (B5S52 05735) and can produce an AI-2 signal (Additional file 15: Figure S7B). A BLAST search of receptors for AI-2 showed that SX309 contains one copy of rbsB (B5S52_21960) encoding the D-ribose $\mathrm{ABC}$ transporter substrate-binding protein. In the SX309 genome, two pairs of QS genes, $q s e \mathrm{~B} / q s e \mathrm{C}$ and $g a c \mathrm{~S} / g a c \mathrm{~A}$, were identified and highly conserved in SX309 and other five Pectobacterium strains.

\section{Two-component system}

The genome of P. carotovorum subsp. brasiliense SX309 contains 19 TCSs (Additional file 17: Table S10). Based 


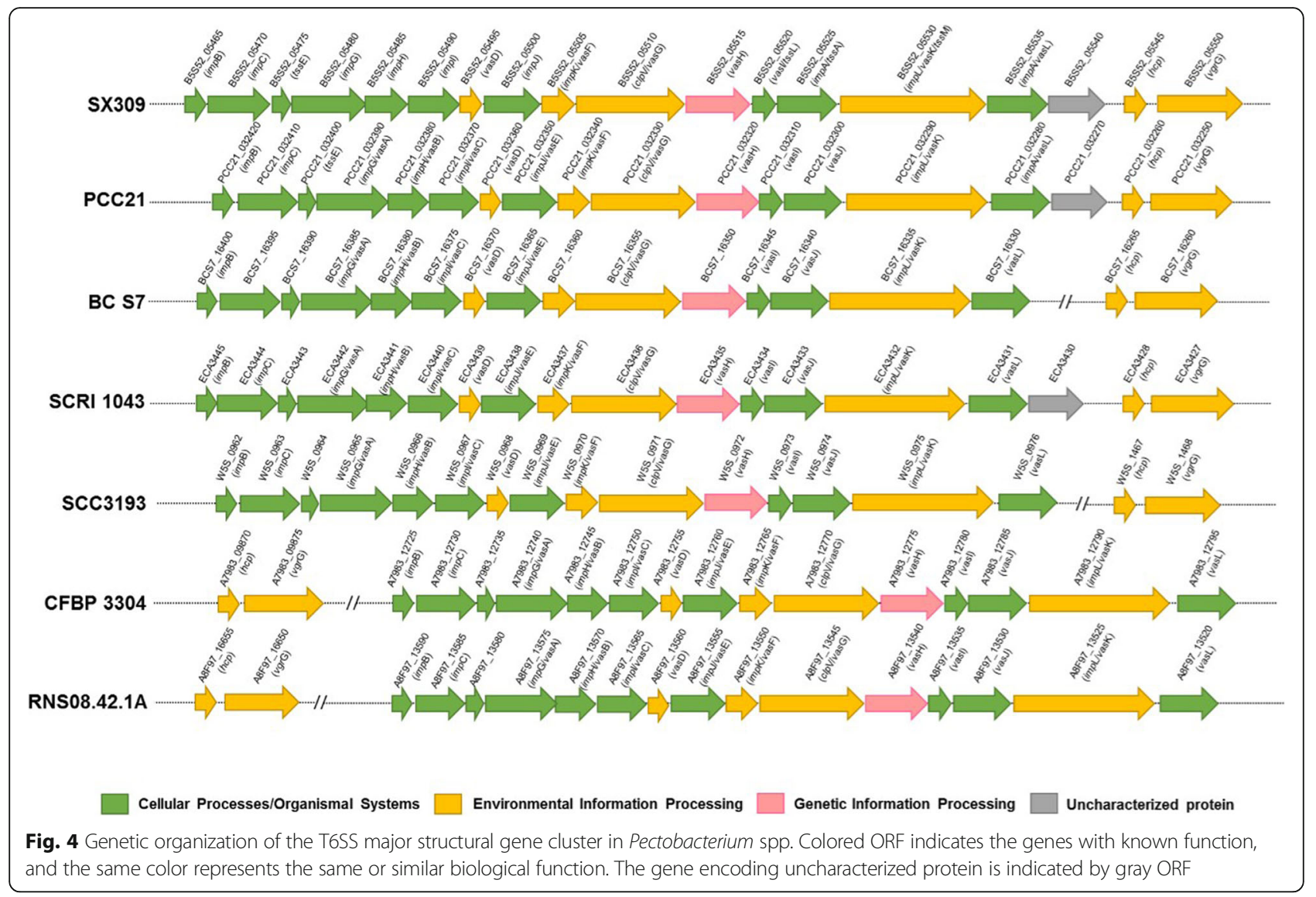

on the homology box, the topological characteristic of $\mathrm{HK}$ and the architecture of the C-terminal domain of RR [53], the 19 TCSs were grouped into five previously described subfamilies. There are nine HK/RR TCSs of the OmpR subfamily, five TCSs of the NarL subfamily, two TCSs of the CitB subfamily, two TCSs of the NtrC subfamily, and one belonging to the chemotaxis subfamily.

Sequence analysis indicated that the phoP-phoQ TCS exists in SX309 (encoded by B5S52_12350B5S52_12355). It has a high similarity (more than 95\%) at the amino acid levels with the phoP-phoQ cluster in other Pectobacterium strains. The genes gacS (B5S52_04715) and gacA (B5S52_08195), which encode a protein of 929 aa and 218 aa respectively, share more than $95 \%$ identity at the amino acid level with those in other Pectobacterium strains. Additionally, in the SX309 genome, 10 other types of putative TCSs have also been identified. They are involved in the regulation of phosphate starvation $(\mathrm{PhoR} / \mathrm{B})$, envelope stress (CpxA/R and $B a e S / R)$, aerobic/anaerobic respiration $(\mathrm{ArcB} / \mathrm{A})$, motility $(\mathrm{Che} A / \mathrm{Y})$, capsular synthesis/virulence $(\mathrm{Rcs} C / \mathrm{D}), \mathrm{K}^{+}$-limitation $(\mathrm{KdpD} / \mathrm{E})$, osmotic stress (EnvZ/OmpR), nitrogen assimilation $(\mathrm{GlnL} / \mathrm{G})$, citrate metabolism (CitA/B), and unknown function (RstB/A and BasS/R) [54] (Additional file 17: Table S10).

\section{Flagellar and chemotaxis genes}

Two sets of genes encoding flagella biosynthetic and chemotactic proteins were found in the genome of $P$. carotovorum subsp. brasiliense SX309 (Additional file 18: Figure S8). The one for flagella biosynthesis is tightly clustered (B5S52_08335- B5S52_08505), and encode 39 proteins (FlhDC, FlhBAE, FlgN K, FliR C, FliA, and FliZ) with high protein similarity among Pectobacterium spp., except for the genes fliC and filD, which showed a low similarity with those in $P$. parmentieri SCC3193 and $P$. parmentieri RNS08.42.1A (Additional file 19: Table S11). These results suggested that the entire flagellar biosynthetic region was probably acquired as a genomic island through horizontal genetic transfer in the Pectobacterium genus. The other set of genes for chemotaxisrelated proteins are split in different clusters in the chromosome of $P$. carotovorum subsp. brasiliense SX309 (B5S52_08290- B5S52_08330, B5S52_00035, B5S52_06425, B5S52_08270, B5S52_10545, B5S52_ 12895, B5S52_14295, and B5S52_21005) (Additional 
file 19: Table S11). BLAST results showed that these chemotactic proteins and chemotaxis family TCSs are highly conserved (average $90 \%$ protein similarity) within the Pectobacterium genus.

\section{Lipopolysaccharide}

The genes involved in the biosynthesis of LPS in SX309 were identified and clustered (Additional file 20: Table S12). Specifically, all the nine genes (lpxACDHBKLM and $w a a \mathrm{~A}$ ) and four genes (waaCEFQ), required for the biosynthesis of the core-lipid A complex [55], are present in the SX309 chromosome. In addition, the four genes involved in the assembly and transport of LPS in Gram-negative bacteria are also present in the SX309 genome (lapB and lptAFG). Furthermore, the O-antigen synthetic protein encoding gene $r f b C$ was also identified. Two gene clusters $(k d s \mathrm{ABCD}$ and $g m h \mathrm{ABCD})$ were also found to be highly conserved among Pectobacterium spp.

Clustered regularly interspaced short palindromic repeats (CRISPR) and CRISPR-associated sequence (Cas) proteins The CRISPR-Cas systems were identified in six Pectobacterium genomes (Additional file 21: Table S13 and Fig. 5). P. carotovorum subsp. brasiliense SX309, P. carotovorum subsp. carotovorum PCC21, P. parmentieri SCC3193, and $P$. parmentieri RNS08.42.1A have two noticeable subtypes of CRISPR-Cas systems. However, P. carotovorum subsp. odoriferum BC S7 and P. atrosepticum SCRI1043 has only one subtype I-E CRISPR-Cas system and one subtype I-F CRISPR-Cas system respectively (Fig. 5). The subtype I-E CRISPR-Cas system in SX309 was composed of cas 1 (B5S52_19965), cas2 (B5S52_19960), cas3 (B5S52_20000), casA (B5S52_19990), casB (B5S52_19985), casC (B5S52_ 19980), casD (B5S52_19975), and casE (B5S52_19970). In addition, the SX309 strain subtype I-E CRISPR-Cas system contains cas1 (B5S52_04200), cas3 (B5S52_04195), csy1 (B5S52_04190), csy2 (B5S52_04185), csy3 (B5S52_ 03935), and csy4 (B5S52_03930) (Additional file 21: Table S13). Among the six strains, these Cas proteins are highly conserved at the amino acid level. Interestingly, the six Pectobacterium strains contain different numbers of CRISPR repeats (Additional file 22: Table S14 and Fig. 5). The CRISPR repeats are absent in $P$. carotovorum subsp. carotovorum PCC21, while other five Pectobacterium strains all have three or more than three CRISPR repeats with different lengths.

Based on the sequences of the CRISPR spacers, the putative CRISPR targets were also analyzed in six Pectobacterium strains using Viroblast or BLAST plasmid searches. The targeted sequences contained diverse phages, including those of Pectobacterium, Erwinia, and Ralstonia, additional bacterial phages, and various types of plasmids (Additional file 22: Table S14). In the SX309 genome, four CRISPR repeats were identified. Specifically, the CRISPR repeat sequence (CGGTTTATCCCCGCTGGCGCGGGGAACAC) conserved in $P$. carotovorum subsp. brasiliense SX309 and P. parmentieri RNS08.42.1A, contained the highest number

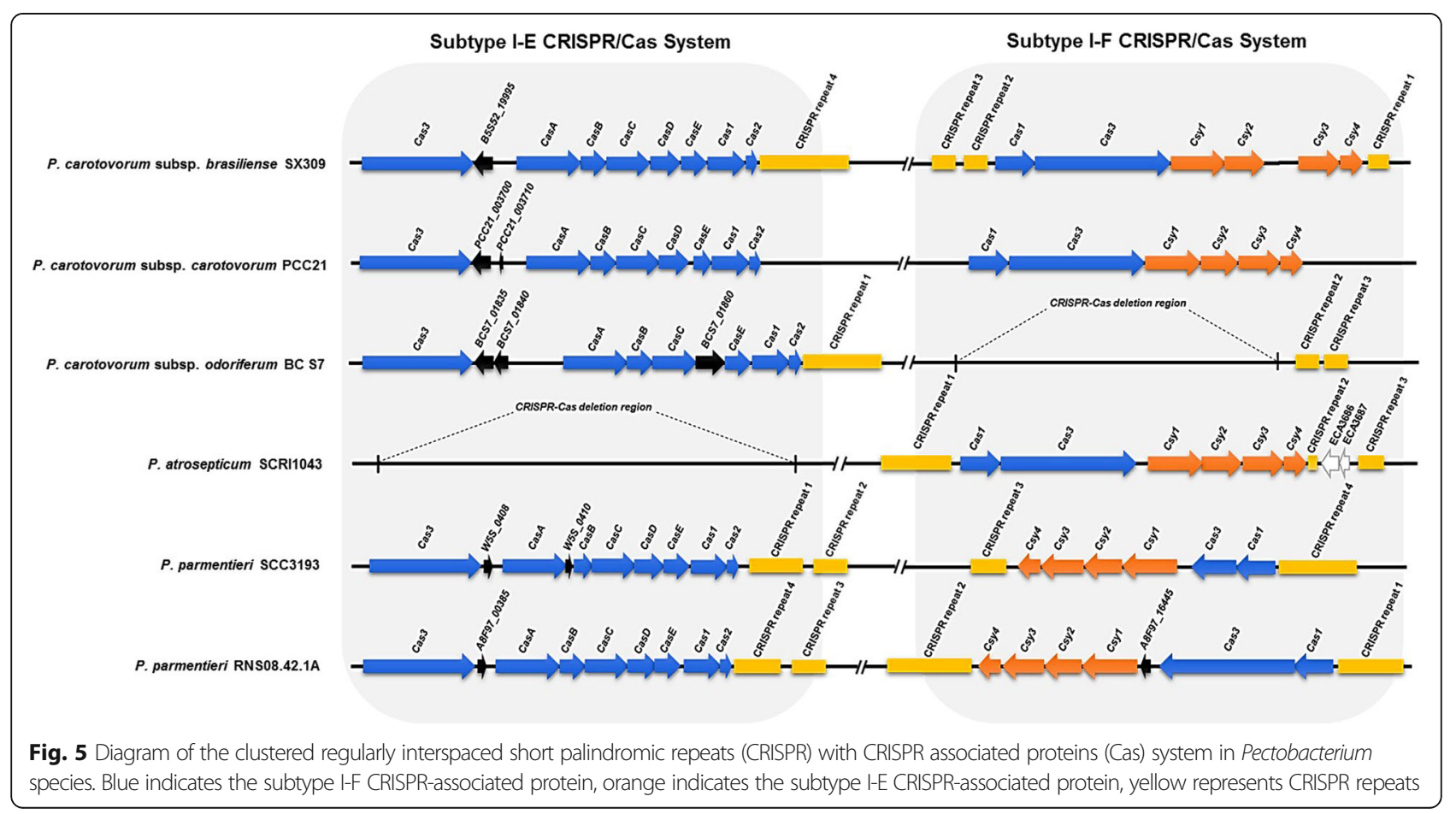


of spacers. There were 35 spacers in $P$. carotovorum subsp. brasiliense SX309 and 31 spacers in $P$. parmentieri RNS08.42.1A. Three of the 35 spacers in SX309 targeted several types of phages, including Erwinia phage ENT90 and Pectobacterium phage ZF40, but did not target plasmids (Additional file 22: Table S14). Four spacers among the 31 in RNS08.42.1A targeted different types of bacteriophages, including Pectobacterium phage phiTE, Pectobacterium phage ZF40, Erwinia phage vB_EamM_ChrisDB, and Erwinia phage phiEa2809 and did not target bacterial plasmids.

\section{Discussion}

Pectobacterium spp. are considered to be broad-host range pathogens, except that $P$. atrosepticum and $P$. parmentieri have been reported almost exclusively from potatoes (Solanum tuberosum) and P. betavasculorum almost exclusively from sugar beets (Beta vulgaris). The taxonomic position of many strains in the Pectobacterium genus has been re-classified in recent years $[2,9$, 10]. For example, Pcc PC1 was classified into P. aroidearum, and P. peruviense, P. polaris and Candidatus P. maceratum were separated from $P$. carotovorum. In this study, Pcb SX309 was assigned to the clade of $P$. carotovorum brasiliense with the other reported $P c b$ strains (BC1 and BAZ12) based on the phylogenetic analysis. This is consistent with the findings of Meng et al [14]. Moreover, ANI and DDH values demonstrated the taxonomic position of $P c b$ SX309. The wide host range of $P c b$ SX309 also agreed with an important feature of $P$. carotovorum $[3,14]$.

PCWDEs including pectinases, cellulases and proteinases are key virulence factors for bacterial pathogenicity of many important plant bacterial pathogens causing soft rot disease [1]. Alignment analysis revealed that the genes related to the production of PCWDEs all exist in various Pectobacterium species and are highly conserved. Previous study showed that Pel and other pectinases including Peh, pectin lyase (Pnl), pectinesterase, and pectin acetylesterase play a major role in the virulence of and tissue maceration by $P$. wasabiae [56]. In our study, Pel, Peh, Cel and Pet were detected in SX309. However, the functions of these proteases in pathogenicity of PcbSX309 still need to be determined.

Bacteria have evolved several sophisticated secretion systems that export a wide range of extracellular enzymes and effector proteins. In Gram-negative bacteria, these secretion systems can range from simple transporters to multi-component complexes and have been classified into six types, including type I through type VI secretion systems [57].

Many Gram-negative bacteria use the ubiquitous type II secretion system (T2SS) to translocate extracellular proteins from the periplasm across the outer membrane
[58]. The T2SS is well-conserved and primarily composed of common secretion and Sec proteins, which are encoded by 12-15 general secretory pathway (Gsp) gene clusters (GspA to GspO and GspS) that are essential for the bacteria [59]. Previous studies have revealed that pectinases and cellulases are secreted by the T2SS in Pectobacterium, and its inactivation led to reduced pathogenicity [60]. T2SSs were also found in D. dadantii, the causal agent of bacterial stem and root rot of sweet potato, and P. carotovorum (formerly called E. carotovorum), which is responsible for soft rot disease in potato and other crops [61]. Moreover, the GspD- GspC T2SS played an important role in $D$. dadantii [62]. The role of T2SS in Pcb SX309 remains to be determined in the future.

T3SSs are used by many Gram-negative pathogenic bacteria to deliver virulence proteins (known as effectors) into host cells. Once inside host cells, the effectors manipulate host defenses and promote bacterial growth [63]. Unlike in many other plant bacterial pathogens, the T3SS in $P$. carotovorum subsp. carotovorum appears to secrete only one effector protein, DspE [64]. Therefore, Pectobacterium seems do not require the T3SS for pathogenicity [21]. T3SS contributes to $P$. carotovorum growth in the leaves of Arabidopsis thaliana [65] at the early stages of infection and contributes to the virulence of P. atrosepticum on Solanum tuberosum [66]. However, it need to be determined whether the virulence of $P c b$ partly depend on T3SS during infection of the host plant.

A promiscuous secretion system, possibly participated in bacterial pathogenicity, is the recently identified type VI secretion systems (T6SS) in diverse Gram-negative bacteria [67]. T6SS gene clusters consist of 13 core genes that are hypothesized to be minimally necessary for function and conserved genes that vary in composition between species [68]. The vgrG (encoding valine/glycine-repeat protein G) gene contribute to the virulence in Acinetobacter baumannii ATCC 19606 [69]. In Acidovorax avenae subsp. avenae strain RS-2, disruption of the genes $p p p \mathrm{~A}$, $c l p \mathrm{~B}, i c m \mathrm{~F}, i m p \mathrm{~J}$ and $i m p \mathrm{M}$ caused the reduction of biofilm formation, and mutation of $p p p \mathrm{~A}, c l p \mathrm{~B}, i c m \mathrm{~F}$ and $h c p$ resulted in the reduction in motility. The vital roles of T6SS in the virulence of strain RS-2 may be partially attributed to the reductions in Hcp secretion, biofilm formation and motility. In the Pectobacterium genus, for the biological functions of the T6SS, researchers have not yielded a generalizable conclusion. In Pcc S1, impG strongly influences the virulence and hypersensitive response [70]. It was demonstrated that the PCWDEs genes (pelA and $p r t \mathrm{~F}$ ) and T6SS genes ( $v g r G$ and $h c p 3$ ) had the same expression profiles regulated by QS. In $P$. atrosepticum SCRI1043, and the hcp and $v g r G$ genes are 
induced in response to potato extracts. However, the virulence of a single gene defective mutant that was interfered in the secretion of Hcp was reported to be stronger than that of the wild-type pathogen in potato tubers [71]. A mutant with double deletions of two machinery encoding clusters spanning 16 (W5S_0962W5S_0978) and 23 (W5S_2418-W5S_2441) genes that included the two putative T6SS encoding loci was modestly affected in its virulence in the potato tuber slice assay [56]. To date, T6SSs in many bacteria may be involved in pathogenic or symbiotic interactions with their hosts. However, more work are needed to define the function of this intriguing system in $P c b$.

Quorum Sensing is a special type of regulation of bacterial gene expression, usually active in conditions of a high population density of bacterial cells. QS systems are widespread among the plant soft-rotting bacteria [7].Previous research showed that Pectobacterium spp. produces two AHL family quorum sensing signals, i.e., $\mathrm{N}$-3-oxooctanoyl-L-homoserine lactone (3-oxo-C8-AHL) and 3-oxohexanoyl-L-homoserine lactone (3-oxo-C6AHL), which are encoded by the luxI homolog expI [72, 73]. The AHL signal was detected by ExpR that belongs to the LuxR family of proteins and was transduced into cellular responses. The inactivation of $\exp \mathrm{I}$ resulted in the decreased production of PCWDEs and decreased virulence [19].

The second QS system, based on the production of the AI-2 signal molecules and controlled by the Sribosylhomocysteine lyase LuxS protein, exists in a wide variety of both Gram-negative and Gram-positive bacteria and is involved in bacterial interspecies communication [74]. The LuxS/AI-2 type QS plays a strain-dependent role in virulence of different Pectobacterium strains. A $l u x \mathrm{~S}$ homolog from a Pectobacterium was first reported in a derivative of $P$. carotovorum subsp. carotovorum ATTn10 and in P. atrosepticum SCRI1043 [75]. Previous study revealed that there is a correlation between the AI-2 level and the production of pectinolytic enzymes. But it lacks orthologs for both known AI-2 receptors: the LuxPQreceptor and the Lsr ABC-transporter [76]. We hypothesize that $\mathrm{RbsB}$ is an alternative to the $\mathrm{AI}-2$ receptors in the Pectobacterium strain. However, the function of the $r b s B$ gene still needs to be validated.

Interestingly, a new kind of autoinducer (AI-3) was discovered in Enterohemorrhagic Escherichia coli (EHEC). AI-3 is perceived by the sensor kinase QseC and its cognate response regulator QseB [77]. Meanwhile, it was found that $q s e \mathrm{C}$ and $q s e \mathrm{~B}$ were both in PcbSX309, Overall, the biological significance of various QS systems, especially the LuxS/AI-2 QS system in SX309 and other Pectobacterium species, remains to be studied further. Previous studies show that the expression of the $r s m \mathrm{~A} / r s m \mathrm{~B}$ genes involved in the regulation of PCWDE biosynthesis is also dependent upon the global regulatory GacA/GacS system [18].

To survive, colonize and cause disease, plantpathogenic bacteria often modulate the expression of their genes using two-component signal transduction systems (TCSs). These systems typically consist of a sensor histidine kinase (HK) and a response regulator (RR) performing a His-Asp phosphotransfer [78].It has been reported that virulence, resistance to magainin II, and the expression of pectate lyase in D. chrysanthemi 3937 were mediated by the response of the PhoP-PhoQ TCSs to $\mathrm{pH}$ and magnesium [79]. Additionally, the GacS/ GacA two-component regulators are involved in the global control of virulence in $P$. carotovorum subsp. carotovorum [80]. However, the functions of these TCSs still need to be addressed.

Bacterial flagella are complex and originated very early as organelles that provide swimming and swarming motilities and play a central role in adhesion, biofilm formation, and host invasion [81]. Flagellar proteins are normally responsible for cell motility and intracellular trafficking, secretion and vesicular transport, while the chemotactic proteins are involved in cell motility and signal transduction [82].In $D$. dadantii 3937, the mutation of $f l i \mathrm{~A}$ encoding a sigma factor eliminated the bacterial motility, and significantly reduced Pel production and the bacterial attachment to plant tissues [82]. Similarly, the inactivation of $f l g \mathrm{~A}, f l i \mathrm{~A}$, and $f l h \mathrm{~B}$ gene abolished the bacterial motility and significantly reduced the bacterial virulence in $P$. carotovorum subsp. carotovorum PCC21 [83]. We have observed that Pectobacterium cells are motile in diseased plant tissues (data not published), but whether the production of PCWDEs and secretion systems that contribute to virulence is coordinated with motility is still unclear. Thus, the functions of flagellar and chemotactic genes in Pectobacterium pathogenicity, especially in pathogen-host plant interactions, remain to be explored.

LPSs were shown to have complex and differing roles depending on their origin and the challenged plant. Previous research reported that different defense response patterns could be induced by the LPS of $P$. atrosepticum and Pseudomonas corrugata in three Solanaceae species, including tobacco, tomato, and potato [84]. Additionally, different signaling pathways could also be activated by LPS in Arabidopsis thaliana cells [85].A previous study showed that LPS are crucial for the optimal growth, survival and virulence of $P$. atrosepticum [86], but the roles of LPS in the SX309 strain remain to be determined.

The CRISPR-Cas system mediate immunity to invading genetic elements such as bacteriophages, viruses and plasmids [87]. Based on the presence of the Cas3, Cas9, and Cas10 proteins, different CRISPR-Cas systems were classified into three major types, type I, II, and III. The 
major types comprise further subtypes (e.g., I-A to I-F), each is characterized by a specific set of proteins [90]. Cas1 is the protein hallmark of CRISPR-mediated immunity, and Cas 1 and Cas2 were found in all CRISPRcontaining organisms [23].

The key factors of the CRISPR-mediated immunity system are small CRISPR RNAs that guide nucleases to complementary target nucleic acids of invading genetic material, generally followed by the degradation of the invader $[88,89]$. Previous studies revealed that the $P$. atrosepticum SCRI1043 CRISPR-Cas system contains six proteins, including Cas1, Cas3, and the four subtype I-F specific proteins Csy1, Csy2, Csy3, and Csy4, and three CRISPR repeats [26]. In P. atrosepticum, the Csy4 protein was identified to be responsible for processing the CRISPR RNAs into crRNAs and appears to interact with itself in the absence of other Cas proteins [90]. In our study, we found $P c c, P c o$, and $P c b$ all harbor two subtypes of CRISPR/CAS system (Type I-E, I-F). In Escherichia coli, primed adaptation by type I-E CRISPR-Cas system occurs after the Cascade-crRNA complex interacts with a fully matching protospacer that is subject to interference [25]. However, there are relatively few reports concerning the CRISPR-Cas system in Pectobacterium species.

T6SS can be deployed as versatile weapons to compete with other bacterial cells or attack simple or higher eukaryotic cells and likely plays an important role in mediating a pathogenic or a symbiotic relationship between bacteria and eukaryotes in various environmental niches [68, 91-94]. Antibacterial effector toxins secreted by T6SSs contributed to the antibacterial functions, which could be neutralized by corresponding antagonistic immunity proteins to preventing self-killing or sibling-intoxication. In Vibrio cholerae, VgrG-3 was found to degrade peptidoglycan and hydrolyse the cell wall of Gramnegative bacteria, and the TsaB (type six secretion antitoxin B) was identified as the immunity protein. In Dickeya dadantii 3937, Rhs played an important role in intercellular competition, which is linked with the VgrG component of T6SS [94]. The functions of T6SSs should be determined in future research.

\section{Conclusion}

This study provided a comprehensive analysis of the complete genome of $P$. carotovorum subsp. brasiliense strain SX309, a causative agent of bacterial soft rot disease. The genomic analysis of strain SX309 has shown that this bacterium belongs to the $P$. carotovorum subsp. brasiliense. The chromosome organization and structure in P. carotovorum subsp. brasiliense strain SX309 is most similar to that of $P$. carotovorum subsp. brasiliense $\mathrm{BC} 1$, which is consistent with the finding that SX309 and BC1 are closely related based on multilocus sequence analysis. To our knowledge, the primary pathogenicity determinants of Pectobacterium are the coordinated production of PCWDEs that macerate host tissue and release nutrients for bacterial growth. These extracellular enzymes are secreted by the T2SS under the control of QS system [17]. Type III secretion system (T3SS) genes are not involved in the secretion of exoenzymes, but they still play a crucial role in Pectobacterium pathogenicity [21]. Compared to other pathogenic bacteria belonging to the Pectobacterium genus, the genome of $P$. carotovorum subsp. brasiliense SX309 encodes many similar virulence factors, including the PCWDE biosynthetic genes, T2SS and T3SS genes, bacterial QS genes, flagella and chemotactic genes. Moreover, comparative analysis revealed that the Pectobacterium strains harbor the type VI secretion system and CRISPR-Cas immune system genes, which were suggested to contribute to bacterial virulence and adaptive immunity. However, the functions of these genes remain to be elucidated in $P$. carotovorum subsp. brasiliense.

In summary, the comprehensive analyses of the genomes of Pectobacterium strains provide new insights for the conservation and evolution processes of virulence elements in these important bacterial pathogens. Knowledge of the variability and specificities of the Pectobacterium organisms could contribute to a better understanding of the molecular mechanisms of unique genetic features and pathogenesis.

\section{Additional files}

Additional file 1: Table S1. Classification and general features of Pectobacterium carotovorum subsp. brasiliense SX309 according to the MIGS recommendations. (DOCX $15 \mathrm{~kb}$ )

Additional file 2: Figure S1. General characteristics of $P$. carotovorum subsp. brasiliense SX309. Image of SX309 cells using transmission electron microscopy (A) and fluorescent microscopy (B). Image of SX309 cells from the exponential growth phase $(C)$ and the stationary phase (D), respectively. (TIF $2925 \mathrm{~kb}$ )

Additional file 3: Figure S2. P. carotovorum subsp. brasiliense SX309 symptoms on representative cucumber ( $\mathrm{A}$, Cucumis sativus) and potato ( $B$, Solanum tuberosum) stems. The bacterial cells were used to inoculate cucumber or potato stem at $10^{8} \mathrm{cfu} \cdot \mathrm{mL}^{-1}$. At 24 hours after inoculation, the soft rot (A) or blackleg (B) symptom were observed and photographed. (TIF $3173 \mathrm{~kb}$ )

Additional file 4: Table S2. Project information. (DOCX 14 kb) Additional file 5: Table S3. Genome statistics. (DOCX 12 kb) Additional file 6: Figure S3. Annotation of $P$. carotovorum subsp. brasiliense SX309 as generated by the Rapid Annotation using Subsystem Technology (RAST, http://rast.nmpdr.org/) webserver. (TIF 2271 kb)

Additional file 7: Table S4. The locus tag information of 165 rRNA genes and five housekeeping genes used for phylogenetic analysis in this study. (DOCX $19 \mathrm{~kb})$

Additional file 8: Figure S4. Phylogenetic tree highlighting the relative position of $P$. carotovorum subsp. brasiliense SX309 within other Pectobacterium, Dickeya, and Erwinia species. The phylogenetic tree was constructed based on six housekeeping genes (16S rRNA, gapA, gyrA, 
atpD, rpoA, rho) according to the aligned gene sequences using maximum likelihoods derived from MEGA 6.0 software. Bootstrap values $(1,000$ replicates) are shown at the branch points. The scale bar indicates 0.02 nucleotide substitution per nucleotide position. The original hosts of bacteria were shown in the brackets. GenBank accession numbers associated to the housekeeping loci of all strains can be found in Additional file 3: Table S4. (TIF $4868 \mathrm{~kb}$ )

Additional file 9: Table S5. Percentage of average nucleotide identities $(\mathrm{ANI})^{\mathrm{a}}$ and in silico DNA-DNA hybridization $(\mathrm{DDH})^{\mathrm{b}}$ among the selected Pectobacterium genomes (XLSX $11 \mathrm{~kb})$

Additional file 10: Figure S5. Dot-plot analysis of linear genomic organization between P. carotovorum subsp. brasiliense SX309 and other six previously fully sequenced Pectobacterium genomes. The X-axis represents the SX309 genome, Y-axis represents PCC21 genome (A), BC S7 genome (B), SCRl1043 genome (C), SCC3193 genome (D), RNS08.42.1A genome (E), and CFBP 3304 genome (F), respectively. Red indicates the alignment sequence in the forward direction, blue indicates the alignment sequence in the reverse direction. (TIF $3562 \mathrm{~kb}$ )

Additional file 11: Figure S6. Production of extracellular enzymes in $P$. carotovorum subsp. brasiliense SX309. Plate assays for the activity of pectate lyase (Pel), polygalacturonase (Peh), cellulase (Cel), and protease (Prt). In the center point of plate, wells were made in agarose media with a no. 2 cork borer and the bottoms were sealed with $0.8 \%(w / v)$ molten agarose. Bacterial cells were grown until early stationary phase at $28^{\circ} \mathrm{C}$ in NB medium (noninduced). After adjustment of the optical density of cell suspensions at $600 \mathrm{~nm}$ to 0.6 by adding sterilized distilled water, $10 \mu \mathrm{ll}$ of the cultures were applied to each well. After incubation at $28^{\circ} \mathrm{C}$, each plate was treated as described in Methods. Three independent experiments had similar results. (TIF $2528 \mathrm{~kb}$ )

Additional file 12: Table S6. Homologs of cell wall-degrading enzyme genes in P. carotovorum subsp. brasiliense SX309 and other Pectobacterium spp. (DOCX $23 \mathrm{~kb}$ )

Additional file 13: Table S7. Identification of homologs of type II, II and Sec-SRP secretion system genes in P. carotovorum subsp. brasiliense SX309 and other Pectobacterium spp. (DOCX $25 \mathrm{~kb}$ )

Additional file 14: Table S8. Genetic elements of T6SS-encoding gene clusters in pathogenic Pectobacterium spp. were summarized and the presence of the key T6SS structure genes is indicated for the analysed genomes. (DOCX $18 \mathrm{~kb}$ )

Additional file 15: Figure S7. The detection of Al-1 and Al-2 QS signal biosynthesis in P. carotovorum subsp. brasiliense SX309. (A) Analysis of Nacyl-homoserine lactone (AHL) produced by $P$. carotovorum subsp. brasiliense SX309. $\beta$-Galactosidase activity of the traG-lacZ fusion in the biosensor strain A. tumefaciens NTL4 (pZLR4) was measured after incubation with AHL extracted from the wild-type SX309. All experiments were performed in triplicate, and error bars indicate standard deviation; those with a different letter are significantly different according to least signification difference test $(P<0.05)$. (B) Induction of bioluminescence in Vibrio harveyi reporter strain BB170 by cell-free medium (CFM) from P. carotovorum subsp. brasiliense SX309. Sterile AB medium and CFM from $5 \mathrm{~mL}$ cultures of $V$. harveyi BB120 were used as negative and positive controls. The baseline is the value when uninoculated (sterile) CFM alone at 2, 4,6 h were used. Each bar represents the mean $( \pm \mathrm{SD})$ of triplicate experiments. (TIF $1825 \mathrm{~kb}$ )

Additional file 16: Table S9. Identification of homologs of quorum sensing genes in P. carotovorum subsp. brasiliense SX309 and other Pectobacterium spp. (DOCX $16 \mathrm{~kb}$ )

Additional file 17: Table S10. Homolog of two-component system encoding genes in P. carotovorum subsp. brasiliense SX309 and other Pectobacterium spp. (XLSX $13 \mathrm{~kb})$

Additional file 18: Figure S8. Physical map of flagellar genes and chemotaxis genes in P. carotovorum subsp. brasiliense SX309. Arrows denote putative transcriptional units. The double slashes indicate long genetic distance. (TIF $1691 \mathrm{~kb}$ )

Additional file 19: Table S11. Identification of homologs of flagellar and chemotaxis genes in P. carotovorum subsp. brasiliense SX309 and other Pectobacterium spp. (XLSX $15 \mathrm{~kb}$ )
Additional file 20: Table S12. Homologs of lipopolysaccharide biosynthesis genes in P. carotovorum subsp. brasiliense SX309 and other Pectobacterium spp. (XLSX $14 \mathrm{~kb})$

Additional file 21: Table S13. Homologs of Clustered regularly interspaced short palindromic repeats (CRISPR)-CRISPR-associated protein (Cas) in P. carotovorum subsp. brasiliense SX309 and other Pectobacterium spp. (XLSX $11 \mathrm{~kb})$

Additional file 22: Table S14. Lists of CRISPR target viruses or plasmids based on spacer sequences among Pectobacterium spp. (XLSX 33 kb)

\section{Abbreviations}

AHL: N-acyl homoserine lactone; ANI: Average nucleotide identity; DDH: DNA-DNA hybridization; COG: Class of genes; LCB: Local collinear blocks; PCWDE: Plant Cell Wall Degrading Enzymes; QS: Quorum sensing; AHL: N-acyl homoserine; LPS: Lipopolysaccharide; CRISPR: Clustered regularly interspaced short palindromic repeat; Cas: CRISPR-associated sequence

\section{Acknowledgments}

We would like to acknowledge Dr. Shilai Xing (Berry Genomics Corporation) in genome data analysis. We want to thank Dr. Jinyun Li and Dr. Doron Temper (Citrus Research and Education Center, Department of Microbiology and Cell Science, University of Florida, USA) for critical review and revision of the manuscript.

\section{Authors' contributions}

$L L, Q W$ and $B J L$ conceived and designed the experiments. $L L$ and $L F Y$ performed the experiments. LL, LFY, YXS, XWX, and ALC analyzed data. LL, $Y X S, X W X, A L C$ and BJL wrote the manuscript with input from all authors. $L L$, QW and BJL revised the manuscript. All authors read and approved the final manuscript.

\section{Funding}

This work was supported by the National Key Research \& Development (R\&D) plan (2017YFD0201600), the Science and Technology Innovation Program, Chinese Academy of Agricultural Sciences (CAAS-ASTIP-IVFCAAS), the Key Laboratory of Horticultural Crops Genetic Improvement, Ministry of Agriculture in China (IVF2017ZF01), and the National Natural Science Foundation of China (31701753). These funding sources supported the publication of this work and data analysis while had no role in study design, data collection, and analysis, interpretation of data and in writing the manuscript.

\section{Availability of data and materials}

GenBank BioProject: This Complete Genome project has been deposited at DDBJ/ENA/GenBank under the BioProject PRJNA379343 and link: https:// www.ncbi.nlm.nih.gov/bioproject/PRJNA379343

GenBank Accession This Complete Genome project has been deposited at DDBJ/ENA/GenBank under the accessions no.: CP020350.1

\section{Ethics approval and consent to participate}

Not applicable.

\section{Consent for publication}

Not applicable.

\section{Competing interests}

The authors declare that they have no competing interests.

\section{Author details}

${ }^{1}$ Institute of Vegetables and Flowers, Chinese Academy of Agricultural Sciences, Beijing 100081, China. ${ }^{2}$ Department of Plant Pathology, College of Plant Protection, China Agricultural University, Beijing 100193, China.

Received: 27 October 2018 Accepted: 23 May 2019

Published online: 13 June 2019

\section{References}

1. Joshi JR, Burdman S, Lipsky A, Yedidia I. Effects of plant antimicrobial phenolic compounds on virulence of the genus Pectobacterium. Res Microbiol. 2015;166:535-45. 
2. Li XY, Ma YL, Liang SQ, Tian Y, Yin SJ, Xie SS, et al. Comparative genomics of 84 Pectobacterium genomes reveals the variations related to a pathogenic lifestyle. BMC Genomics. 2018;19:889.

3. Zhang Y, Fan Q, Loria R. A re-evaluation of the taxonomy of phytopathogenic genera Dickeya and Pectobacterium using whole-genome sequencing data. Syst Appl Microbiol. 2016;39:252-9.

4. Sareh BR, Heshmat R, Masoud SB, Emilia LS, María AL, Pablo RP. Characterization of Pectobacterium species from Iran using biochemical and molecular methods. Eur J Plant Pathol. 2011;129:413-25.

5. Nabhan S, De Boer SH, Maiss E, Wydra K. Pectobacterium aroidearum sp. nov. , a soft rot pathogen with preference for monocotyledonous plants. Int J Syst Evol Microbiol. 2013;63:2520-5.

6. Czajkowski R, Pérombelon M, Jafra S, Lojkowska E, Potrykus M, van der Wolf J, et al. Detection, identification and differentiation of Pectobacterium and Dickeya species causing potato blackleg and tuber soft rot: a review. Ann Appl Biol. 2015;166:18-38.

7. Khayi S, Raoul d, Essarts Y, Quêtu-Laurent A, Moumni M, Hélias V, Faure D. Genomic overview of the phytopathogen Pectobacterium wasabiae strain RNS 08.42.1A suggests horizontal acquisition of quorum-sensing genes. Genetica. 2015;143:241-52.

8. Park TH, Choi BS, Choi AY, Choi IY, Heu S, Park BS. Genome sequence of Pectobacterium carotovorum subsp. carotovorum strain PCC21, a pathogen causing soft rot in Chinese cabbage. J Bacteriol. 2012;194:6345-6.

9. Huang YF, Liu CY, Wang H, Guan TS, Liu L, Yu SY. Bioinformatic analysis of the complete genome sequence of Pectobacterium carotovorum subsp. brasiliense BZA12 and candidate effector screening. J Plant Pathol. 2018:1$11 \mathrm{https} / / /$ doi.org/10.1007/s42161-018-0126-7.

10. Duarte $V$, de Boer SH, Ward $\sqcup$, de Oliveira AM. Characterization of atypical Erwinia carotovora strains causing blackleg of potato in Brazil. J Appl Microbiol. 2004;96:535-45.

11. Werra PD, Bussereau F, Keiser A, Ziegler D. First report of potato blackleg caused by Pectobacterium carotovorum subsp. brasiliense in Switzerland. Plant Dis. 2015;99:551.

12. Onkendi EM, Ramesh AM, Kwenda S, Naidoo S, Moleleki L. Draft genome sequence of a virulent Pectobacterium carotovorum subsp. brasiliense isolate causing soft rot of cucumber. Genome Announc. 2016;4:e01530-15.

13. Fujimoto T, Yasuoka S, Aono Y, Nakayama T, Ohki T, Sayama M, et al. First report of potato blackleg caused by Pectobacterium carotovorum subsp. brasiliense in Japan. Plant Dis. 2016;101:241.

14. Meng XL, Chai AL, Shi YX, Xie XW, Ma ZH, Li BJ. Emergence of bacterial soft rot in cucumber caused by Pectobacterium carotovorum subsp. brasiliense in China. Plant Dis. 2016;101:279-87.

15. Toth IK, Bell KS, Holeva MC, Birch PR. Soft rot erwiniae: from genes to genomes. Mol Plant Pathol. 2003;4:17-30.

16. Mashavha ML. Characterisation of Pectobacterium carotovorum subsp. brasiliense isolates causing blackleg and soft rot diseases of potato in South Africa; 2013.

17. Chatterjee A, Cui Y, Liu Y, Dumenyo CK, Chatterjee AK. Inactivation of rsmA leads to overproduction of extracellular pectinases, cellulases, and proteases in Erwinia carotovora subsp. carotovora in the absence of the starvation/cell density-sensing signal, N-(3-oxohexanoyl)-L-homoserine lactone. Appl Environ Microbiol. 1995;61:1959-67.

18. Cirou A, Uroz S, Chapelle E, Latour X, Orange N, Faure D, et al. Quorum sensing as a target for novel biocontrol strategies directed at Pectobacterium. Recent Developments in Management of Plant Diseases. Netherlands: Springer; 2010. p. 121-31.

19. Moleleki LN, Pretorius RG, Tanui CK, Mosina G, Theron J. A quorum sensing-defective mutant of Pectobacterium carotovorum subsp. brasiliense 1692 is attenuated in virulence and unable to occlude xylem tissue of susceptible potato plant stems. Mol Plant Pathol. 2017;18:32-44.

20. Alfano JR, Collmer A. Type III secretion system effector proteins: double agents in bacterial disease and plant defense. Annu Rev Phytopathol. 2004; 42:385-414.

21. Kim HS, Ma B, Perna NT, Charkowski AO. Phylogeny and virulence of naturally occurring type III secretion system-deficient Pectobacterium strains. Appl Environ Microbiol. 2009;75:4539-49.

22. Masum MMI, Yang YZ, Li B, Olaitan OS, Chen J, Zhang Y, et al. Role of the genes of type $\mathrm{VI}$ secretion system in virulence of rice bacterial brown stripe pathogen Acidovorax avenae subsp. avenae strain RS-2. Int J Mol Sci. 2017; 18:2024.
23. Makarova KS, Haft DH, Barrangou R, Brouns SJ, Charpentier E, Horvath $\mathrm{P}$, et al. Evolution and classification of the CRISPR-Cas systems. Nat Rev Microbiol. 2011;9:467-77.

24. Hille F, Richter H, Wong SP, Bratovič M, Ressel S, Charpentier E. The biology of CRISPR-Cas: backward and forward. Cell. 2018;172:1239-59.

25. Semenova E, Savitskaya E, Musharova O, Strotskaya A, Vorontsova D, Datsenko KA, et al. Highly efficient primed spacer acquisition from targets destroyed by the Escherichia coli type I-E CRISPR-Cas interfering complex. Proc Natl Acad Sci U S A. 2016;113:7626-31.

26. Richter C, Gristwood T, Clulow JS, Fineran PC. In vivo protein interactions and complex formation in the Pectobacterium atrosepticum subtype I-F CRISPR/Cas system. PLoS One. 2012;7:e49549.

27. Berlin K, Koren S, Chin CS, Drake JP, Landolin JM, Phillippy AM. Assembling large genomes with single-molecule sequencing and locality-sensitive hashing. Nat Biotechnol. 2015;33:623-30.

28. Grant JR, Stothard P. The CGView Server: a comparative genomics tool for circular genomes. Nucleic Acids Res. 2008;36:W181-4.

29. Tatusova T, DiCuccio M, Badretdin A, Chetvernin V, Nawrocki EP, Zaslavsky L, et al. NCBI prokaryotic genome annotation pipeline. Nucleic Acids Res. 2016; 44:6614-24.

30. Lowe TM, Chan PP. tRNAscan-SE On-line: integrating search and context for analysis of transfer RNA genes. Nucleic Acids Res. 2016;44:W54-7.

31. Lagesen $K$, Hallin P, Rødland EA, Staerfeldt HH, Rognes T, Ussery DW. RNAmmer: consistent and rapid annotation of ribosomal RNA genes. Nucleic Acids Res. 2007;35:3100-8.

32. Aziz RK, Bartels D, Best AA, DeJongh M, Disz T, Edwards RA, et al. The RAST Server: rapid annotations using subsystems technology. BMC Genomics. 2008:9:75.

33. Bendtsen JD, Nielsen H, von Heijne G, Brunak S. Improved prediction of signal peptides: SignalP 3.0. J Mol Biol. 2004;340:783-95.

34. Krogh A, Larsson B, von Heijne G, Sonnhammer EL. Predicting transmembrane protein topology with a hidden Markov model: application to complete genomes. J Mol Biol. 2001;305:567-80.

35. Tamura K, Stecher G, Peterson D, Filipski A, Kumar S. MEGA6: molecular evolutionary genetics analysis version 6.0. Mol Biol Evol. 2013;30:2725-9.

36. Yoon SH, Ha SM, Lim J, Kwon S, Chun J. A large-scale evaluation of algorithms to calculate average nucleotide identity. Antonie Van Leeuwenhoek. 2017;110:1281-6.

37. Auch AF, von Jan M, Klenk HP, Göker M. Digital DNA-DNA hybridization for microbial species delineation by means of genome-to-genome sequence comparison. Stand Genomic Sci. 2010;2:117-34.

38. Darling AC, Mau B, Blattner FR, Perna NT. Mauve: multiple alignment of conserved genomic sequence with rearrangements. Genome Res. 2004;14: 1394-403.

39. Kurtz S, Phillippy A, Delcher AL, Smoot M, Shumway M, Antonescu C, et al. Versatile and open software for comparing large genomes. Genome Biol. 2004:5:R12.

40. Altschul SF, Gish W, Miller W, Myers EW, Lipman DJ. Basic local alignment search tool. J Mol Biol. 1990;215:403-10.

41. Chen F, Mackey AJ, Stoeckert CJ Jr, Roos DS. OrthoMCL-DB: querying a comprehensive multi-species collection of ortholog groups. Nucleic Acids Res. 2006;34:D363-8.

42. Chen $\mathrm{H}$, Boutros $\mathrm{PC}$. VennDiagram: a package for the generation of highly-customizable Venn and Euler diagrams in R. BMC Bioinformatics. 2011;12:35.

43. Wang $Y$, Huang $H$, Sun $M$, Zhang Q, Guo D. T3DB: an integrated database for bacterial type III secretion system. BMC Bioinformatics. 2012;13:66.

44. Rajput A, Kaur K, Kumar M. SigMol: repertoire of quorum sensing signaling molecules in prokaryotes. Nucleic Acids Res. 2016;44:D634-9.

45. Barakat M, Ortet P, Whitworth DE. P2CS: a database of prokaryotic twocomponent systems. Nucleic Acids Res. 2011;39:D771-6.

46. Grissa I, Vergnaud G, Pourcel C. CRISPRFinder: a web tool to identify clustered regularly interspaced short palindromic repeats. Nucleic Acids Res. 2007;35: W52-7.

47. Bloemberg GV, O'Toole GA, Lugtenberg BJ, Kolter R. Green fluorescent protein as a marker for Pseudomonas spp. Appl Environ Microbiol. 1997;63: 4543-51.

48. Field D, Garrity G, Gray T, Morrison N, Selengut J, Sterk P, et al. The minimum information about a genome sequence (MIGS) specification. Nat Biotechnol. 2008;26:541-7. 
49. Ma B, Hibbing ME, Kim HS, Reedy RM, Yedidia I, Breuer J, et al. Host range and molecular phylogenies of the soft rot enterobacterial genera Pectobacterium and Dickeya. Phytopathology. 2007:97:1150-63.

50. Filloux A, Hachani A, Bleves S. The bacterial type VI secretion machine: yet another player for protein transport across membranes. Microbiology. 2008; 154:1570-83.

51. Miller MB, Bassler BL. Quorum sensing in bacteria. Annu Rev Microbiol. 2001; 55:165-99.

52. Põllumaa L, Alamäe T, Mäe A. Quorum sensing and expression of virulence in Pectobacteria. Sensors. 2012;12:3327-49.

53. Mascher T, Helmann JD, Unden G. Stimulus perception in bacterial signaltransducing histidine kinases. Microbiol Mol Biol Rev. 2006;70:910-38.

54. Heermann R, Fuchs TM. Comparative analysis of the Photorhabdus luminescens and the Yersinia enterocolitica genomes: uncovering candidate genes involved in insect pathogenicity. BMC Genomics. 2008;9:40.

55. Raetz CR, Reynolds CM, Trent MS, Bishop RE. Lipid A modification systems in gram-negative bacteria. Annu Rev Biochem. 2007;76:295-329.

56. Nykyri J, Niemi O, Koskinen P, Nokso-Koivisto J, Pasanen M, Broberg M, et al. Revised phylogeny and novel horizontally acquired virulence determinants of the model soft rot phytopathogen Pectobacterium wasabiae SCC3193. PLoS Pathog. 2012:8:e1003013.

57. Costa TR, Felisberto-Rodrigues C, Meir A, Prevost MS, Redzej A, Trokter M, et al. Secretion systems in Gram-negative bacteria: structural and mechanistic insights. Nat Rev Microbiol. 2015;13:343-59.

58. Korotkov KV, Sandkvist M, Hol WG. The type II secretion system: biogenesis, molecular architecture and mechanism. Nat Rev Microbiol. 2012;10:336-51.

59. Sandkvist M. Type II Secretion and Pathogenesis. Infect Immun. 2001;69: 3523-35.

60. Filloux A. The underlying mechanisms of type II protein secretion. Biochim Biophys Acta. 2004;1694:163-79.

61. Toth IK, Birch PR. Rotting softly and stealthily. Curr Opin Plant Biol. 2005;8: 424-9.

62. Wang X, Pineau C, Gu S, Guschinskaya N, Pickersgill RW, Shevchik VE. Cysteine scanning mutagenesis and disulfide mapping analysis of arrangement of GspC and GspD protomers within the type 2 secretion system. J Biol Chem. 2012;287:19082-93.

63. Grant SR, Fisher EJ, Chang JH, Mole BM, Dangl JL. Subterfuge and manipulation: type III effector proteins of phytopathogenic bacteria. Annu Rev Microbiol. 2006;60:425-49.

64. Hogan CS, Mole BM, Grant SR, Willis DK, Charkowski AO. The type III secreted effector DspE is required early in Solanum tuberosum leaf infection by Pectobacterium carotovorum to cause cell death, and requires Wx(3-6)D/E motifs. PLoS One. 2013;8:e65534.

65. Rantakari A, Virtaharju O, Vähämiko S, Taira S, Palva ET, Saarilahti HT, et al. Type III secretion contributes to the pathogenesis of the soft-rot pathogen Erwinia carotovora: partial characterization of the hrp gene cluster. Mol Plant-Microbe Interact. 2001;14:962-8.

66. Holeva MC, Bell KS, Hyman LJ, Avrova AO, Whisson SC, Birch PR, et al. Use of a pooled transposon mutation grid to demonstrate roles in disease development for Erwinia carotovora subsp. atroseptica putative type II secreted effector (DspE/A) and helper (HrpN) proteins. Mol Plant-Microbe Interact. 2004;17:943-50.

67. Coulthurst SJ. The Type VI secretion system-a widespread and versatile cell targeting system. Res Microbiol. 2013;164:640-54.

68. Chang JH, Desveaux D, Creason AL. The ABCs and $123 \mathrm{~s}$ of bacterial secretion systems in plant pathogenesis. Annu Rev Phytopathol. 2014;52: 317-45.

69. Wang JF, Zhou ZH, He F, Ruan Z, Jiang Y, Hua XT, et al. The role of the type $\mathrm{VI}$ secretion system $\mathrm{vgr} G$ gene in the virulence and antimicrobial resistance of Acinetobacter baumannii ATCC 19606. PLoS One. 2018;13:e0192288.

70. Yang LK, Wang JJ, Wang H, Wang CT, Fan JQ. Functional analysis of type VI secretion system in Pectobacterium carotovorum subsp.carotovorum. Chinese Society for Plant Pathology Annual Symposium; 2015. p. 315.

71. Mattinen L, Somervuo P, Nykyri J, Nissinen R, Kouvonen P, Corthals G, et al. Microarray profiling of host-extract-induced genes and characterization of the type $\mathrm{VI}$ secretion cluster in the potato pathogen Pectobacterium atrosepticum. Microbiology. 2008;154:2387-96.

72. Bell KS, Sebaihia M, Pritchard L, Holden MT, Hyman L, Holeva MC, et al. Genome sequence of the enterobacterial phytopathogen Erwinia carotovora subsp. atroseptica and characterization of virulence factors. Proc Natl Acad Sci U S A. 2004;101:11105-10.
73. Chatterjee A, Cui Y, Hasegawa H, Leigh N, Dixit V, Chatterjee AK. Comparative analysis of two classes of quorum-sensing signaling systems that control production of extracellular proteins and secondary metabolites in Erwinia carotovora subspecies. J Bacteriol. 2005;187:8026-38.

74. Vendeville A, Winzer K, Heurlier K, Tang CM, Hardie KR. Making 'sense' of metabolism: autoinducer-2, LuxS and pathogenic bacteria. Nat Rev Microbiol. 2005;3:383-96.

75. Coulthurst SJ, Lilley KS, Salmond GP. Genetic and proteomic analysis of the role of luxS in the enteric phytopathogen, Erwinia carotovora. Mol Plant Pathol. 2006;7:31-45.

76. Rezzonico F, Duffy B. Lack of genomic evidence of Al-2 receptors suggests a non-quorum sensing role for luxS in most bacteria. BMC Microbiol. 2008;8:154.

77. Gotoh Y, Eguchi Y, Watanabe T, Okamoto S, Doi A, Utsumi R. Twocomponent signal transduction as potential drug targets in pathogenic bacteria. Curr Opin Microbiol. 2010;13:232-9.

78. Stock AM, Robinson VL, Goudreau PN. Two-component signal transduction. Annu Rev Biochem. 2000;69:183-215.

79. Haque MM, Tsuyumu S. Virulence, resistance to magainin II, and expression of pectate lyase are controlled by the PhoP-PhoQ two-component regulatory system responding to $\mathrm{pH}$ and magnesium in Erwinia chrysanthemi 3937. J Gen Plant Pathol. 2005:71:47-53.

80. Eriksson AR, Andersson RA, Pirhonen M, Palva ET. Two-component regulators involved in the global control of virulence in Erwinia carotovora subsp. carotovora. Mol Plant-Microbe Interact. 1998;11:743-52.

81. Liu R, Ochman H. Stepwise formation of the bacterial flagellar system. Proc Natl Acad Sci U S A. 2007;104:7116-21.

82. Jahn CE, Willis DK, Charkowski AO. The flagellar sigma factor fliA is required for Dickeya dadantii virulence. Mol Plant-Microbe Interact. 2008;21:1431-42.

83. Lee DH, Lim JA, Lee J, Roh E, Jung K, Choi M, et al. Characterization of genes required for the pathogenicity of Pectobacterium carotovorum subsp. carotovorum Pcc21 in Chinese cabbage. Microbiology. 2013;159:1487-96.

84. Desender S, Klarzynski O, Potin P, Barzic MR, Andrivon D, Val F. Lipopolysaccharides of Pectobacterium atrosepticum and Pseudomonas corrugata induce different defence response patterns in tobacco, tomato, and potato. Plant Biol. 2006;8:636-45.

85. Mohamed KH, Daniel T, Aurélien D, El-Maarouf-Bouteau H, Rafik E, ArbeletBonnin D, et al. Deciphering the dual effect of lipopolysaccharides from plant pathogenic Pectobacterium. Plant Signal Behav. 2015;10:e1000160.

86. Evans TJ, Ind A, Komitopoulou E, Salmond GP. Phage-selected lipopolysaccharide mutants of Pectobacterium atrosepticum exhibit different impacts on virulence. J Appl Microbiol. 2010;109:505-14.

87. Barrangou R, Fremaux C, Deveau H, Richards M, Boyaval P, Moineau S, et al. CRISPR provides acquired resistance against viruses in prokaryotes. Science. 2007;315:1709-12.

88. Haurwitz, R. E. . (2012). The crispr endoribonuclease csy4 utilizes unusual sequence- and structure-specific mechanisms to recognize and process crrnas - escholarship. Electronic Thesis \& Dissertations.

89. Louwen R, Staals RH, Endtz HP, van Baarlen P, van der Oost J. The role of CRISPR-Cas systems in virulence of pathogenic bacteria. Microbiol Mol Biol Rev. 2014;78:74-88.

90. Przybilski R, Richter C, Gristwood T, Clulow JS, Vercoe RB, Fineran PC. Csy4 is responsible for CRISPR RNA processing in Pectobacterium atrosepticum. RNA Biol. 2011;8:517-28.

91. Hood RD, Singh P, Hsu F, Güvener T, Carl MA, Trinidad RR, et al. A type VI secretion system of Pseudomonas aeruginosa targets a toxin to bacteria. Cell Host Microbe. 2010;7:25-37.

92. Russell AB, Hood RD, Bui NK, LeRoux M, Vollmer W, Mougous JD. Type VI secretion delivers bacteriolytic effectors to target cells. Nature. 2011;475: $343-7$.

93. Silverman JM, Brunet YR, Cascales E, Mougous JD. Structure and regulation of the type VI secretion system. Annu Rev Microbiol. 2012;66:453-72.

94. Yang $X B$, Long $M X$, Shen $X H$. Effector-immunity pairs provide the T6SS nanomachine its offensive and defensive capabilities. Molecules. 2018 . 23:1009.

\section{Publisher's Note}

Springer Nature remains neutral with regard to jurisdictional claims in published maps and institutional affiliations. 